Original Research Paper

\title{
The Watershed Structures in Controlling Runoff - Case Study of Sardasht Basin in IRAN
}

\author{
${ }^{1}$ Seyedeh Zahra Hosseini-Teshnizi, ${ }^{2}$ Ghodratollah Davoudi, \\ ${ }^{3}$ Seyedeh Laleh Razavi and ${ }^{4 *}$ Kaveh Ostad-Ali-Askari \\ ${ }^{I}$ Department of Water Engineering, Agricultural College, Isfahan University of Technology, Isfahan, Iran \\ ${ }^{2}$ Allameh Tabataba'i University, Faculty of Management and Accounting, Tehran, Iran \\ ${ }^{3}$ Department of Watershed Management Engineering, College of natural Resources and Marine Sciences, \\ Tarbiat Modares University, Noor, Mazandaran, Iran \\ ${ }^{4^{*}}$ Department of Civil Engineering, Najafabad Branch, Islamic Azad University, Najafabad, Iran
}

Article history

Received: 15-10-2019

Revised: 15-01-2020

Accepted: 24-02-2020

Corresponding Author:

Kaveh Ostad-Ali-Askari

Department of Civil

Engineering, Najafabad Branch,

Islamic Azad University,

Najafabad, Iran

Email: kaveh.oaa2000@gmail.com

\begin{abstract}
In order to investigate the performance of constructed structures in Sardasht watershed, Soil and Water Assessment Tools model for simulation of runoff and sediment during the studied period of 1996-2012 was carried out for two cases of existence and absence of flood control structures. From 2007 onwards by performing watershed operations in these sub-basins, the average runoff rate decreased about $250 \mathrm{l} / \mathrm{s}$ for subbasin 1 and $150 \mathrm{l} / \mathrm{s}$ for sub-basin 3 . This indicates the flood was controlled in these basins. On average, the runoff volume has decreased by 0.25 and $0.15 \mathrm{~m}^{3}$ in the sub-basins 1 and 3 respectively in the presence of the structure compared to the absence of structures. A daily, Monthly simulation time stage and a continuous-time step restrict the usage of the SWAT pattern for comprehensive, occurrence-based flood simulation. The occurrence of acridities and unexpected projections in numerous sectors of IRAN, also the density on basic conveniences precious by mass growth, has owing to a broader difference in deliberation to the problematic of water straight in the alliance. Calibrating a hydrologic model of Sardasht Basin. Using SWAT. Subjective Workload Assessment Technique (SWAT) is a multidimensional scaling method designed to assess time load, mental effort load and stress load. According to the results of MannKendall Test, Watershed management in the Sardasht basin for flood control and runoff can be considered acceptable. Before the watershed operation, the occurrence of runoff with the probability of $80 \%$ was zero, which after the operation, the probability of occurrence was reduced by $60 \%$, indicating a positive effect construction of flood and sediment control structures in the Sardasht basin. The results of the hydrological regime curve show that the changes in the monthly runoff ratio to the average monthly runoff before the watershed operations had been more. Due to the limitations, current Soil and Water Assessment Tools simulations in tropical and subtropical regions face a series of problems related to relative humidity, water balance and sediment. Soil and Water Assessment Tools model is also used to estimate the maximum daily flow rate.
\end{abstract}

Keywords: Flood, Runoff, Sedimentation, Watershed Management, Water Basin, Watershed Structure

\section{Introduction}

The occurrence of droughts and unpredictable floods in different parts of IRAN, as well as the pressure on natural resources caused by population growth, has led to a wider shift in attention to the issue of water management in the community. Watershed management is an activity that plans, implements and manages projects. It plans for 
maintaining, rehabilitating, developing and operating optimally from renewable natural resources in the water basins. The present report is basically an assessment of the watershed management performed in Sardasht water basin in Chaharmahal and Bakhtiari province. The results of this research can be used to explain the regional planning methods, with emphasis on the role of flood control structures and the limitation of water and soil resources in determining the uses and activities. In general, the type and extent of loading on the study basin. The method is based on field operations and the registration of the location and physical characteristics of the constructed structures. At first, the basic and necessary information was collected and the accuracy and validity of the reports were reviewed. The rainfall was estimated using the method of coordinated lines. Then runoff from precipitation was done according to the physical characteristics of the basin. Then the runoff generated before and after the watershed operation. Also, it is observed that approximately rainfall ratio to monthly rainfall before the operations was equal, but there was a less productive runoff. It confirms the decreasing trend of Sardasht's monthly runoff. Collecting rainwater using techniques and methods in arid and semi-arid basins to provide more water for agriculture, drinking and industry are termed water extraction. Swat model simulates the unsteady flow well. In order to be more precise, the Sardasht basin is divided into three sub-basins that the structures constructed for watershed management are located in the first and third sub-basins. Plant growth in the Soil and Water Assessment Tool (SWAT) is a critical process for the quality of ecohydrological modeling. It is affected by factors such as evaporation, soil erosion, etc.

Humanity will turn to the use of natural resources to provide their immediate needs. Inappropriate utilization of resources causes regeneration and decreases soil permeability, the decay of vegetation, increased flood, erosion intensification, downstream sedimentation and other problems. Considering the dry climate of Iran, research and planning on soil and water resources are essential for the conservation of natural resources and development of IRAN. Especially in the absence of rainfall, a large volume of atmospheric precipitation is wasted in rainy seasons and sometimes caused floods. On the other hand, to manage the process of destroying these resources in IRAN on the one hand and to create appropriate and efficient management for optimal use of water resources in different regions of IRAN, on the other hand, large-scale watershed management, implementation of scientific programs and solutions to achieve this, it is on the agenda. Watershed management is an activity that plans, implements and manages projects and plans to maintain, rehabilitate, develop and exploit optimally the renewable natural resources in the water basins.
SWAT is one of the mathematical mockups that is extensively applied for such determinations. For scheming the basin discharge, the prototypical needs meteorological information, for example precipitation, temperature, wind speed, solar radiation and relative humidity, in addition to physiographic information connected to the basin surface, for example curve number and roughness factor. The current research is essentially an evaluation of the watershed organization completed in Sardasht watershed in Chaharmahal and Bakhtiari province in Iran. At this period, an examination of the information together from the process in the Sardasht watershed, also evaluates the events done Watershed. In an assessment organization, the determination of directing the application of a watershed organization strategy and classifying possible fortes or faintness by deteriorating to contrast positive watershed organization strategies with ineffective watershed organization strategies. It can be covered the method for the measurable and qualitative application of the scheme factors. This investigation was directed with the goal of assessing the result of sedimentary rock dams on the hydrological point of Sardasht watershed. Evaluating the existing watershed process pursues to realize how operative the watershed process has been in its numerous sizes. the consequences of this investigation can be applied to clarify local development in the description of applies and doings and in over-all, the kind and quantity of loading in the education basin. The consequences of investigations display that the application of watershed organization in watersheds has played a significant part in monitoring surface runoffs. The determination of this investigation is the quantifiable assessment of the properties of the process of the watersheds applied on the hydrological mechanisms of the Sardasht River in Chaharmahal and Bakhtiari province applying hydrologic exhibiting and arithmetical examination.

\section{The Necessity of the Research}

The occurrence of droughts and unpredictable floods in different parts of Iran, as well as the pressure on natural resources caused by population growth, have led to the widening of the conditions for attention to the issue of water management in the community. Accordingly, in order to make optimal use of these resources, the watershed management has implemented macro-level plans to implement practical measures to achieve this. In this regard, the implementation of various watershed projects in small and large basins has increased in the past years and has followed different views among villagers, managers and experts.

In this regard, various plans such as conservation and improvement of the rangeland condition or the construction of an earth-fill dam have been implemented 
to control flood and erosion in various basins. Evaluation of these plans in the stages of study, implementation and monitoring of its effects will lead to an appropriate setting for improvement of future control and effectiveness methods, in addition to qualitative and quantitative control of ongoing projects.

The present research is basically an assessment of the watershed management performed in Sardasht watershed in Chaharmahal and Bakhtiari province in Iran. At this stage, an analysis of the data collected from the operation in the Sardasht watershed, also assesses the activities carried out Watershed. In an evaluation system, the purpose of canalizing the implementation of a watershed management plan and identifying potential strengths or weaknesses by failing to compare successful watershed management plans with unsuccessful watershed management plans. It can be paved the way for the quantitative and qualitative implementation of the project indicators.

The most important objectives of assessing water management projects are to know precisely the efficiency of watershed management with regional conditions, evaluate the more accurate operation of the operation in order to prevent the repetition of errors, as well as promote appropriate methods tested and provide useful management solutions in the future.

A quantitative assessment of water management projects is essential in order to analyze their effects and make the right decisions in the optimal implementation of such plans in similar circumstances. The results of the assessment can be effective in helping to achieve different goals of the watershed management activities, including flood control.

This research was conducted with the aim of evaluating the effect of sedimentary rock dams on the hydrological point of Sardasht watershed. Assessing the current watershed operation seeks to find out how effective the watershed operation has been in its various dimensions. The amount of stored water, reducing erosion, improving vegetation and reducing the number of flood events are among the issues that have been addressed in the evaluation issue.

\section{Innovation to Applying to SWAT in this Study}

The performance evaluation of flood and sediment control plans has not been carried out in the Sardasht basin until now. Preliminary studies of scientific papers for this study to enhance the safety of water and soil based on the concept of sustainable development can be presented as an innovation in this study.

This study emphasizes the role of flood control structures and the limitation of water and soil resources. Therefore, the results of this research can be used to explain regional planning in the designation of uses and activities and in general, the type and amount of loading in the study basin.

\section{How to Study}

The method is based on field operations and the registration of the location and physical properties of the constructed structures. Today, due to overexploitation, the status of water and earth is in critical condition. Over the past forty years, watershed management plans have been implemented in natural resources for the control of intra-regional and extra-regional dangers. But despite four decades of executive work, the destruction of these resources is still ongoing and the measures taken are generally inadequate. In addition, there is still no coherent effort to assess and find the reasons for the failure of these projects.

Multiple research steps are as follows:

1. Collecting the basic and necessary information and checking the validity and reliability of the reports provided. This step is carried out through field operations. To comply with the description of the services provided by the Employer Company, the project consultant has been implemented

2. Reviewing the integration report in terms of technical, regional and facilities of the implementing organization and its appropriateness to the site

3. Preparation of a complete list of operations proposed in the plan with the fieldwork and administrative outputs

To this end, the following steps have been taken into consideration in this plan:

1. Estimation of the precipitation basin using the method of coordinated lines

2. Estimation of precipitation runoff due to the physical characteristics of the basin

3. Evaluation of runoff produced before and after the watershed operation

4. Applying different assessment methods for runoff created in the basin

5. Results

6. Conclusion

Today, soil erosion is one of the most serious problems in developing countries and in many developed countries. To reduce the environmental and economic impacts of erosion caused by improper land use management, it is necessary to adopt measures at farm and water basin.

\section{History of Studies}

Soil erosion is a continuous process that has existed since the formation of land and the human being involved with animal husbandry and agriculture. The erosion has changed the appearance of the land as seen 
today. Obviously, given the impossibility of inhibiting and stopping geological erosion, on the one hand and the continued interference of human beings in exploiting soil, water and plant resources on the other, in the future, this process will be continued. Exacerbated erosion is a phenomenon that is caused by the unwitting and profligate interference of humankind in nature. It destroys the soil that is the bed of production on Earth. According to the studies on soil erosion, based on available statistics and data, with an erosion, every $1 \mathrm{~cm}$ of soil, about $4 \%$ of its fertility is reduced (Ahmadi, 1999).

At present, extensive studies have been done on the role of watershed management in changing the behavior of water basins around the world. In the United States, the evaluation of the performance of water drainage projects has been carried out for a long time over 67 years, with various objectives. Many researchers, such as Doty (1971), Noble (1963) and Satterland (1962), have evaluated the role of the biological and mechanical operation of watersheds in reducing sediment and runoff. They emphasize that the success of water management measures depends on the two factors of soil and water conservation compatibility with the characteristics and characteristics of water basins and their impact on the establishment of vegetation as a sustainability factor and the natural component of each water basin.

Watershed management means managing water basins is an activity that involves planning, implementation and management of projects and plans for the conservation, rehabilitation and development of optimal utilization of renewable natural resources in water basins. Watershed projects control two erosion considerations: First, the type of soil that is protected and the second, the amount of erosion and sediment that is under control. The shape and severity of soil erosion are a function of several factors such as climate, topography, geology, land use status, type and percentage of vegetation and surface runoff conditions. The geological impact and type of land use are important in the intensity and amount of erosion. Various parameters including natural and artificial factors affect the amount of erosion in each basin. If only natural factors exist, the erosion is normal and is below the threshold, which does not need to be controlled, but if human activities affect the soil and the earth, the erosion value will exceed the threshold and the erosion will be exacerbated. There are several ways to erosion control. One of these divisions is the biological and mechanical erosion control. In this regard, it is necessary to investigate the level of watershed management in the water basins in Iran and its impact on sediment degradation. Recent studies show that destructive floods occur in most parts of Iran. The investigations show that the increase in flood events in the $1991 \mathrm{~s}$ is about 10 times more than in the 1961s (IHA, 2001).
The results of researches show that the implementation of watershed management in watersheds has played an important role in controlling surface runoffs. To minimize flood peak, various methods such as sequential reservoirs have been investigated (Karbowski, 1993).

Simonovic (2002) has proposed the use of a combination of construction and non-structural operations to contain floods. To control the flood, some scholars point out the principled use of land as a suitable strategy for managing watersheds (Friesecke, 2004). In this regard, watershed management and how land use in flood formation and its small changes make it very influential.

Satterland (1962) provides three indicators of economic considerations, performance, organizational and managerial constraints for assessing the performance of natural resource projects as a criterion. FAO (1995) considers seven indicators of organizational, socioeconomic, essential resource utilization, environmental expansion, water resources expansion and economic downturn reduction for project appraisal. Biroudian (1994) emphasizes soil conservation and economic evaluation of these projects in northern watershed basins of Iran in four aspects of cost including conservation costs, flood and sediment control costs, cost of damages and cost of product cuts.

The Office of Studies and Assessment of the Watershed Management Department of Iran, with the publication of the evaluation guide (2003), provided seven indicators including biological index, sediment index, rainfall preservation index, flood index, soil conservation and erosion index, environmental index and finally a comprehensive management index for evaluating projects. In this study, by determining the appropriate evaluation indexes of the implemented projects in the form of an evaluation model from the review stage to the implementation and then examined step by step. Causes of success or failure of projects. Therefore, a qualitative model has been used to achieve this goal.

In this model, the proposed design is based on the seven main indicators and the relevant indexes based on the five categories of ranking and its status is determined in terms of performance. Khoubfekr (2001), in his research on socio-economic, social and technical assessment of watershed activities in Sistan and Baluchestan province, in a social discussion, considered the public's satisfaction with water activities as one of the important factors. In this plan, $100 \%$ of the people have expressed their satisfaction with the Watershed. Kowsar (1993), in his project "Desertification with flood spreading", demonstrated that the implementation of this water drainage plan provides a better context for the development of native plants.

Farm income has increased, cattle grazing capacity has increased 10 times. The ability to produce fast- 
growing tree species in these networks has reached 10 ton/hec per year. Bani Asadi (1995) in his research entitled the study of the impact of Bam watershed design on the socio-economic status of residents of the Bam basin. The implementation of the project in the region has led many locals in the region to work at the station. There has also been a decrease in immigration rates in the region. Lammersen et al. (2002) simulated the effects of engineering operations on the Rhine River in the Netherlands on peak times during the return periods of 200, 500 and 1250 years, using their results. The results showed that the delayed structures reduced the peak flow to $45 \mathrm{~m}^{3} / \mathrm{s}$. The peak discharge correction structures increased by an average of $243 \mathrm{~m}^{3} / \mathrm{s}$. Nowadays, the use of the ability of hydrological models to play a role in simulating the effects of management activities in the decision-making process has played a decisive role (Roo et al., 2003).

Shieh et al. (2007) used Hydrologic Engineering Center's Hydraulic Modeling System (HEC-HMS) and Hydrologic Engineering Centers River Analysis System (HEC-RAS) software to simulate the flow and investigate the effect of flood control structures in the Tingong basin of Taiwan. Shokoohi (2007) evaluated the effect of 140 Gabion structures and three reservoirs in the upstream of Behbahan city watershed using the HEC-HMS model. It was found that the construction of reservoir structures in the upper reaches of urban watersheds is suitable for flood control. Results of tolerance approach Viscosity, Rotational Viscometer (RVA) and Thrombin Time (TT) Test showed that the effect on the flow characteristics of structures at the level $(\alpha<0.05)$, has been significant. Castillo et al. (2007) evaluated the effect of correctional structures on the morphology of the canal in the province of Murcia, Spain, using a combination of bedding materials and cross-sectional shape of the canals. They concluded that the structures caused erosion in their habitats and that the slope of the drainage channels was reduced by sedimentation.

Cheng (1989) has studied river flow changes in order to determine the consequences of this after harvesting pine trees in the Beete Infested Watershed in southern England. Using the results of the method of paired catchment basins for evaluating changes in the Camp Creak River after total abandonment of more than $30 \%$ of trees in comparison with adjacent watershed showed that the results of this method are in agreement with the findings of research carried out with other methods.

Lee et al. (2010) in a West African region, using (SWAT) model, showed that changing the basins with forest, pasture and bushes to agricultural lands or urban basins would change the natural hydrologic conditions in a watershed. This change is due to an increase in surface water volume, a decrease in the nutrition of groundwater resources and river water and changes in the amount and severity of erosion and sediment. For the calibration of the SWAT model, SWAT Calibration and Uncertainty Procedures (SWAT-CUP) software and the Sequential Uncertainty Fitting (SUFI-2) algorithm have been used. The initial idea of this algorithm was presented by Abbaspour et al. (2007).

This algorithm is a method for calibrating and analyzing the uncertainty of the SWAT model simultaneously. The SWAT-CUP software has been linked to the SWAT model. The reason for the selection of the SUFI-2 program in this study is that it is able to manage a large number of parameters and measured data at several stations simultaneously. In addition, the program can analyze the sensitivity, uncertainty, calibration and validation simultaneously. The model was calibrated for the period 2002-2011 and validated for the period from 1996 to 2001.

Regarding the importance and necessity of performing watershed operations in Chaharmahal and Bakhtiari province, the occurrence of severe floods and erosion in this province. Evaluation of the performance of implemented measures can lead to making better decisions in reducing flood damage to the villages of the basin adjacent to the outlet of the watershed studied. The purpose of this research is the quantitative evaluation of the effects of the operation of the watersheds implemented on the hydrological components of the Sardasht River in Chaharmahal and Bakhtiari province using hydrologic modeling and statistical analysis.

The watershed has the following features:

- It is not only a range but also a range of land

- It has an outlet along the mainstream with its own drainage range

- It is a complex system with interconnected relationships consisting of the natural, time variable, spatial, social, economic, political and institutional factors

- Economically, it is a production process

\section{Concept of Watershed Management}

The Productivity of water, soil, plants and animals by humans without causing damage to nature or with minimal damage is called watershed management. Also, the concept of Watershed management is based on the knowledge of renewable resources for sustainable development.

The purpose of the watershed management is to apply a set of measures and changes in land use, vegetation and other measures of structural and nonstructural that are carried out in a water basin to achieve the watershed management. 
In planning and deciding the water basin, it is important to:

1. The formal method of social performance based on management for locals by examining scientific information and theory when making decisions based on water basins

2. Real social interaction between scientists and people based on the need for significant investment in time and energy, given that scientists are developing personal relationships with people in terms of mutual trust and exchange of information. This experience is based on the development of a general conceptual model of interaction between scientists and people in the community based on the management of the field of agriculture in the agricultural field

An important aspect of scientific integration is based on social decision making and the conceptual conditions of the environment. The important goal is consistent with a variety of flow management methods, with decisions on human practices and agricultural perspectives.

Watershed projects include smaller components that are referred to as operations and include three groupings: Structural, biological and managerial groups. The purpose of the watershed management is the implementation of a set of measures and changes in land use, vegetation cover and other measures of instrumental and non-structural measures carried out in a watershed to achieve the objectives of the watershed. Figure 1 shows the relationship between design, project, operation and watershed management.

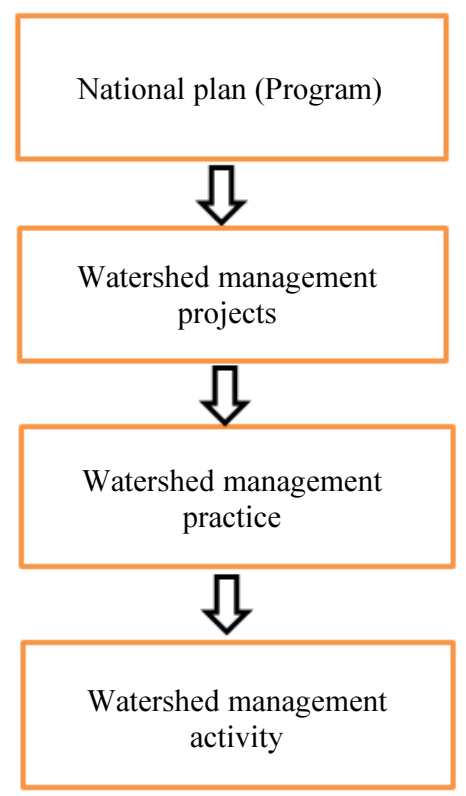

Fig. 1: Plan, Project, operations and watershed activities

\section{Financial Consequences}

The Following are the consequences of physical consequences, effects and financial consequences. For example, reducing sedimentation in the canal will reduce the cost of dredging. In the latter case, the financial impact of the implementation of the project. Another example is the implementation of the project has led to an increase in agricultural production, which is the same financial effect of the project. Increasing production may increase the income of the inhabitants of the catchment basin, which is the financial consequence of the implementation of the project.

\section{Social Consequences}

In addition to financial implications, the implementation of the project may increase employment or reduce the migration of fishermen. Increasing employment and reducing the immigration of the watershed is one of the social consequences of implementing watershed projects.

\section{Environmental Consequences}

These consequences usually result from a series of events occurring in the ecosystem. This can be attributed to changes in groundwater quality, soil erosion, sedimentation, changes in the type of ecosystems and the sustainability of biodiversity, groundwater levels, salinity and alkalinity of the soil and marshy land.

\section{Evaluation and Monitoring}

The two monitoring and evaluation words that are often used together are essential components of planning and managing a water management project. Monitoring: The process of observing, measuring and reporting objective benefits over the lifetime of a watershed is a systematic measure of the quantitative indicators of a watershed design to determine the extent to which achievement of predetermined goals is used. The monitoring will collect the necessary information on the actual condition of the watershed in its implementation at specified intervals in order to allow for the modification of the activities of the plan. Evaluation: A process that seeks to analyze and quantify the data collected from the monitoring activity, in fact, evaluate the data, organize the data from the monitoring, compare it with other data and present the results to the planners, managers and people involved in the watershed management in the right way.

\section{The Concept of Monitoring and Evaluation}

Evaluation with the concept of supervision has a fundamental difference since monitoring is a continuous process and during the implementation of the program, immediate correction is made for any deviation from the operational objectives. If the evaluation is done 
specifically at a distinct point in the life cycle of a program. In evaluations, we need a benchmark in order to know if a program has reached its multiple goals. The Indicator is a characteristic or industry that can be measured to evaluate a program in terms of outcomes or costs. Indicators are necessarily simplified by a more complex reality. In addition, indicators can be quantitative or qualitative.

Effectiveness, in effect, is the concept of the degree to which the objectives of a plan or project are achieved (Hyman, 1985). But in Effectiveness Evaluation, the problem is the non-perceptibility of goals. That is, in quantitative and apparent terms, determining the amount of achievement is difficult. Projects often goals are diverse, sometimes together, in conflict or may not quantifiable not as one of its particular conception. This is why the use of targets in evaluating the effectiveness of the special cases to consider, first, for the achievement of objectives in the effectiveness evaluation should be output and ultimate impact of programs and projects or general economic impact social payments (Hyman, 1985).

Various outcomes of the implementation of programs, projects and projects of natural resources in the analysis of the effects are:

- Functional Consequences are the desired effects of an innovation resulting from the implementation of plans and plans in the socio-economic framework of the watershed

- Non-Functional Consequences are undesirable effects of the implementation of a plan or plan in the socio-economic system of the watershed
- Direct Consequences are those changes that occur in a socioeconomic system as a result of implementing a project or project immediately

- Indirect Consequences are the changes that occur in the socio-economic framework of the watershed due to the direct effects of the implementation of a plan.

- Overt Consequences are changes that are identified by the members of the social system of the watershed and they are intended

- Covert Consequences are the changes that are not intended and not recognizable by members of the social system of the field

\section{The Study Water Basin}

Sardasht watershed is located $59.45 \mathrm{~km}^{2}$ in the city of Lordegan in Chaharmahal and Bakhtiari province in Iran. The range of this basin is located between the geographical coordinates of $50^{\circ}, 049^{\prime}, 24^{\prime \prime}, 50^{\circ}, 59^{\prime}, 27^{\prime \prime}$ Eastern Longitude and $31^{\circ}, 19^{\prime}, 56^{\prime \prime}$ to $31^{\circ}, 24^{\prime}, 30^{\prime \prime}$ Northern Latitudes. The maximum height of the basin is located in the southeast of the basin with a height of 3652 and the minimum height is located in the northwest of the basin with a height of $1900 \mathrm{~m}$ above sea level. Rig Mountain and Shah Mountain are important elevations of the region. In terms of the division of the study basin, Sardasht basin is part of the Karoon river basin, which consists of three sub-basins. In watershed studies, in order to better understand the hydrologic characteristics and prioritize the implementation of the planned programs, the whole watershed is divided into several sub-basins. Figure 2 shows the location of flood control structures on the network of waterways in each sub-basin.

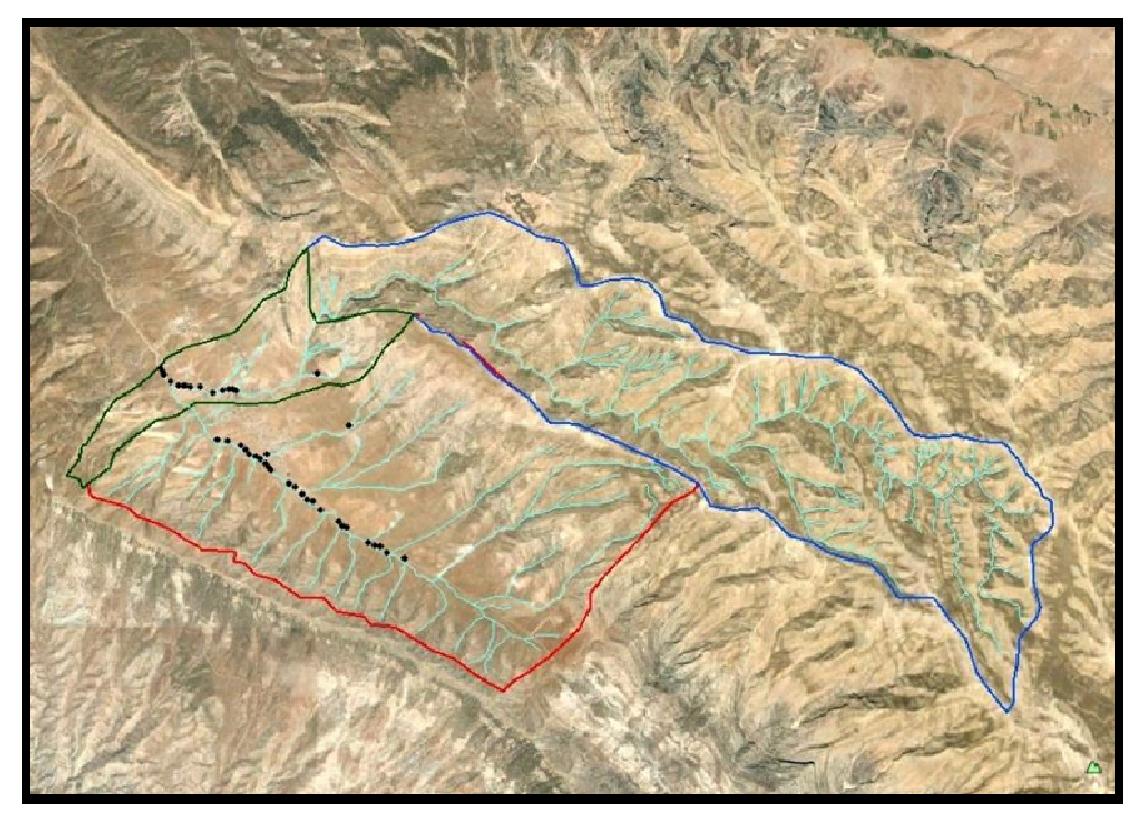

Fig. 2: Location of structures constructed in the Sardasht sub-basins 
The area of Sardasht watershed is equal to $53.30 \mathrm{~km} 2$ and its environment is $65,696 \mathrm{~km}$. In general, the characteristics of the basins in the study basin are determined for all sub-basins separated and are presented in Table 1 Fig. 3 and 4 show an overview of the built-in sections and the study basin.

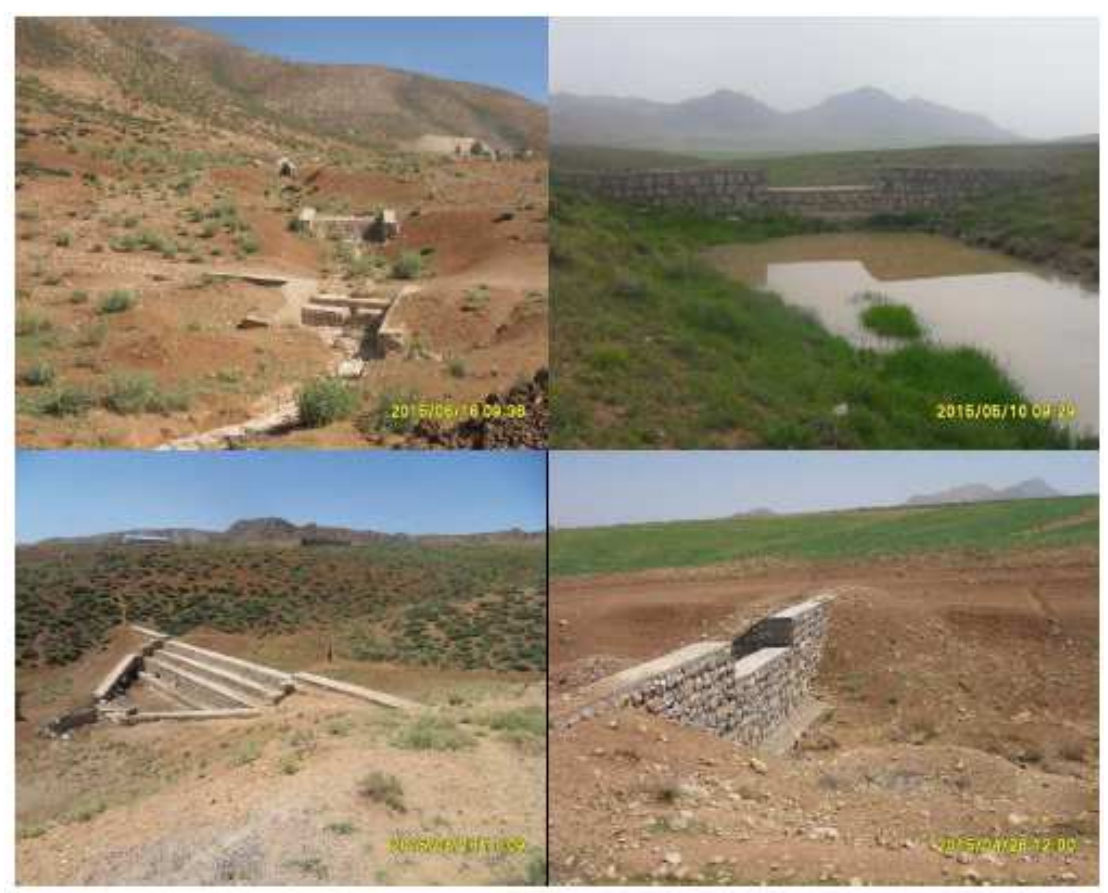

Fig. 3: The sedimentary rock dams for control of flood and sediment in Sardasht basin

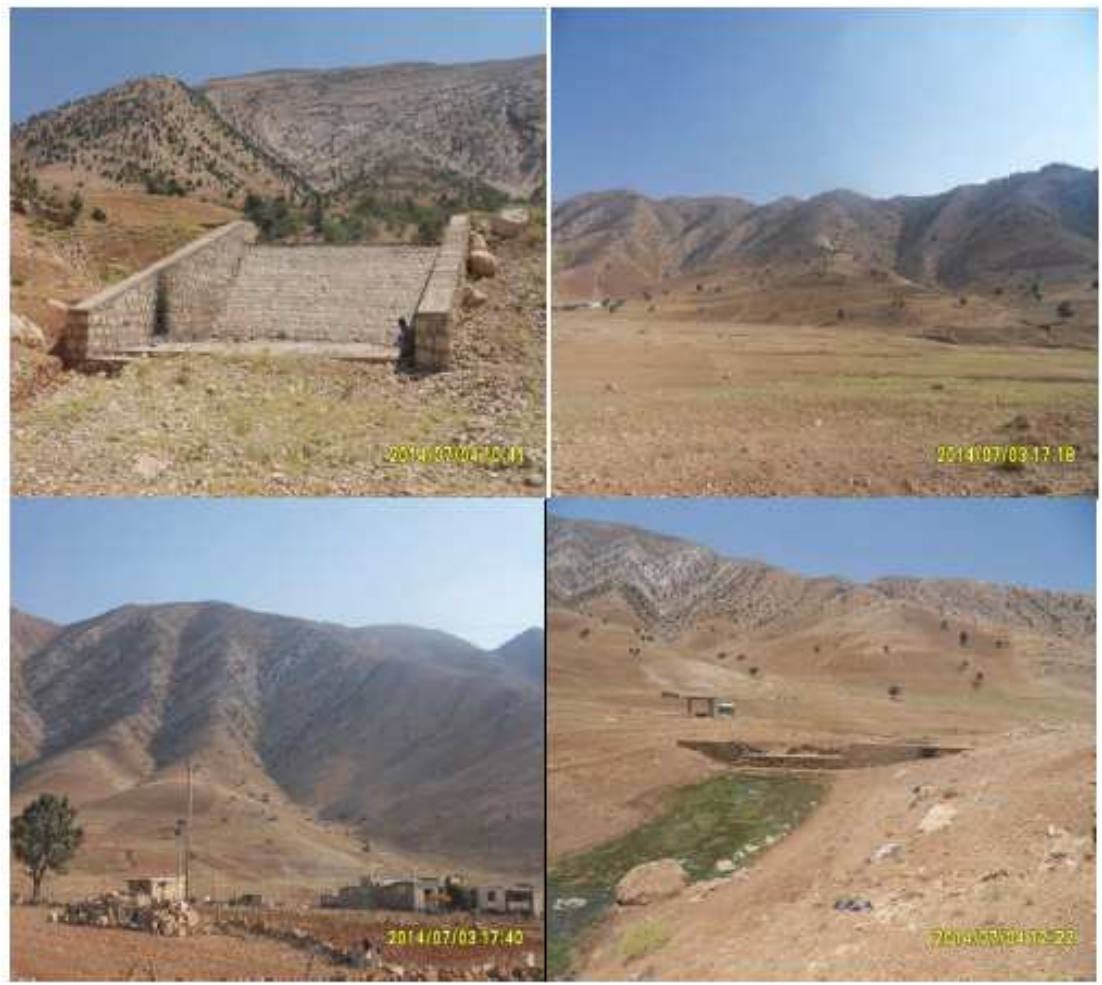

Fig. 4: View of Sardasht basin 


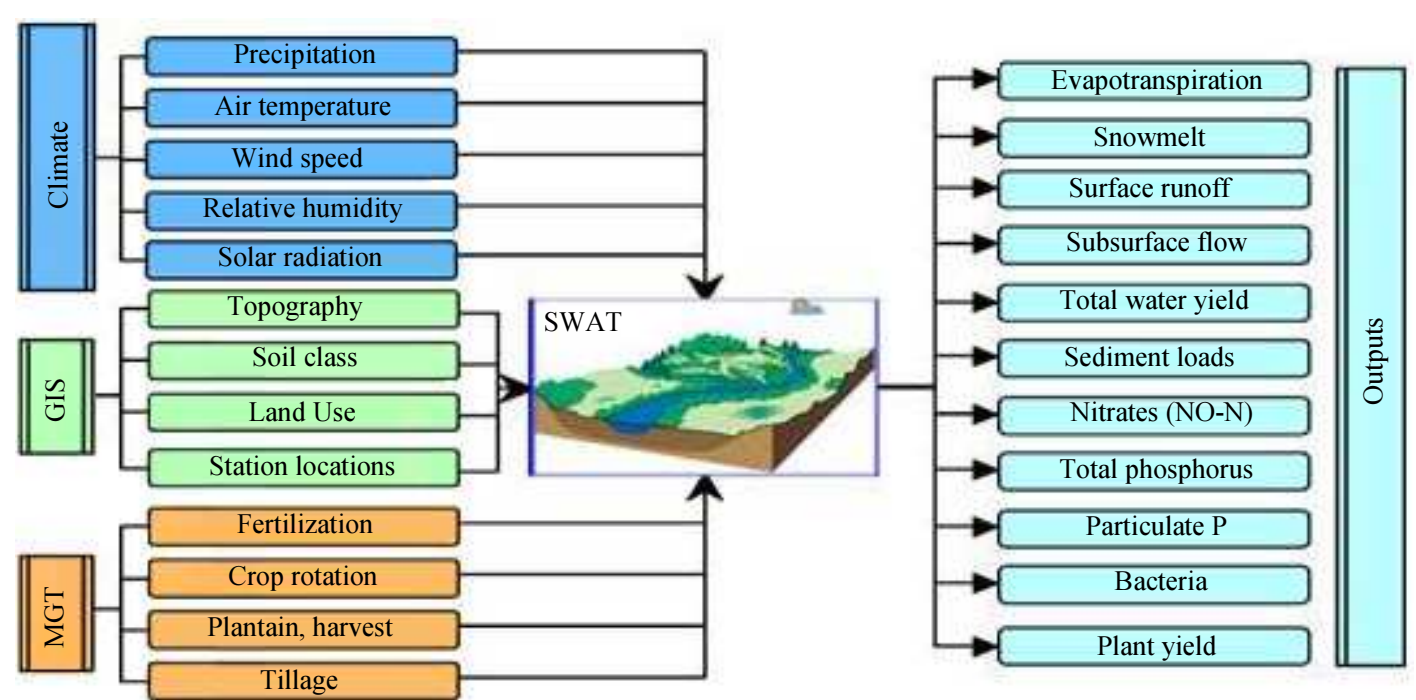

Fig. 5: Inputs and outputs of the SWAT model

Table 1. Specifications of sub-basins in the study basin

\begin{tabular}{llll}
\hline Unit of work & sub-basin 1 & sub-basin 2 & sub-basin 3 \\
\hline Area $\left(\mathrm{km}^{2}\right)$ & 5.3 & 22.9 & 25.2 \\
Environment $(\mathrm{km})$ & 14.18 & 29.61 & 22.17 \\
Length of Basin $(\mathrm{km})$ & 4478.27 & 11639.29 & 6843.77 \\
Minimum height(m) & 1970 & 2083 & 1994 \\
Maximum height(m) & 2629 & 3541 & 3178 \\
Middle Height $(\mathrm{m})$ & 2145.273 & 3006.29 & 2352.364 \\
The average slope $(\%)$ & 26.73 & 41.84 & 32.70 \\
\hline
\end{tabular}

After studying the study basin in the first step, runoff and sediment produced at the level of the basin should be estimated in the time interval before and after the watershed operation.

Today, in many parts of the world, due to the lack of sufficient facilities and the lack of information and statistics on runoff and sediment production, models are used. Among the most widely used models in runoff and sediment estimation studies in watershed management, a SWAT conceptual hydrologic model, whose performance in reported abundance research, is mentioned, can be mentioned.

The SWAT model has a physical basis and can be used in watersheds that do not have regular inventories. For modeling purposes, a domain may be divided into several sub-regions. The SWAT model also simulates spatial detail by dividing a basin into a large number of subbasins. The SWAT model enables the various physical processes to be simulated for the entire watershed. The main parts of the model include hydrology, climate, Hydrologic Reaction Units (HRUs), wetlands, underground water, erosion, plant growth, nutrient elements, pesticides, land management and flow routing.

In this model, each basin is subdivided into several sub-basins and each of the sub-basins into several HRUs that are homogeneous for land use and soil characteristics.
Initially, water in the soil, surface runoff, nutrient cycle, sediment, plant growth and management methods are calculated for each unit of hydrological reaction and then for each sub-basin as a weighted average.

The SWAT hydrologic model is based on the equilibrium water balance and flow regression is performed using both Maskingham and variable-saving methods. This model simulates the runoff run using Curve Numbers (CN) and the influence of the GreenAmp penetration runoff. The SWAT model calculates the maximum runoff using an argumentative method.

The inputs and outputs of the SWAT model are generally shown in Fig. 5.

\section{Materials and Methods}

\section{Complete of the Required Data by the SWAT Model}

Meteorological data was prepared from relevant organizations. Data after the elimination of defects were converted to Geographic Information System (GIS) format, then, in order to increase the accuracy of the estimation of the sediment, the land use map was also prepared according to the OLI satellite imagery of Landsat 8 of 2014 according to the following. A view of the Landsat 8 satellite image in the Sardasht basin is shown in Fig. 6. 


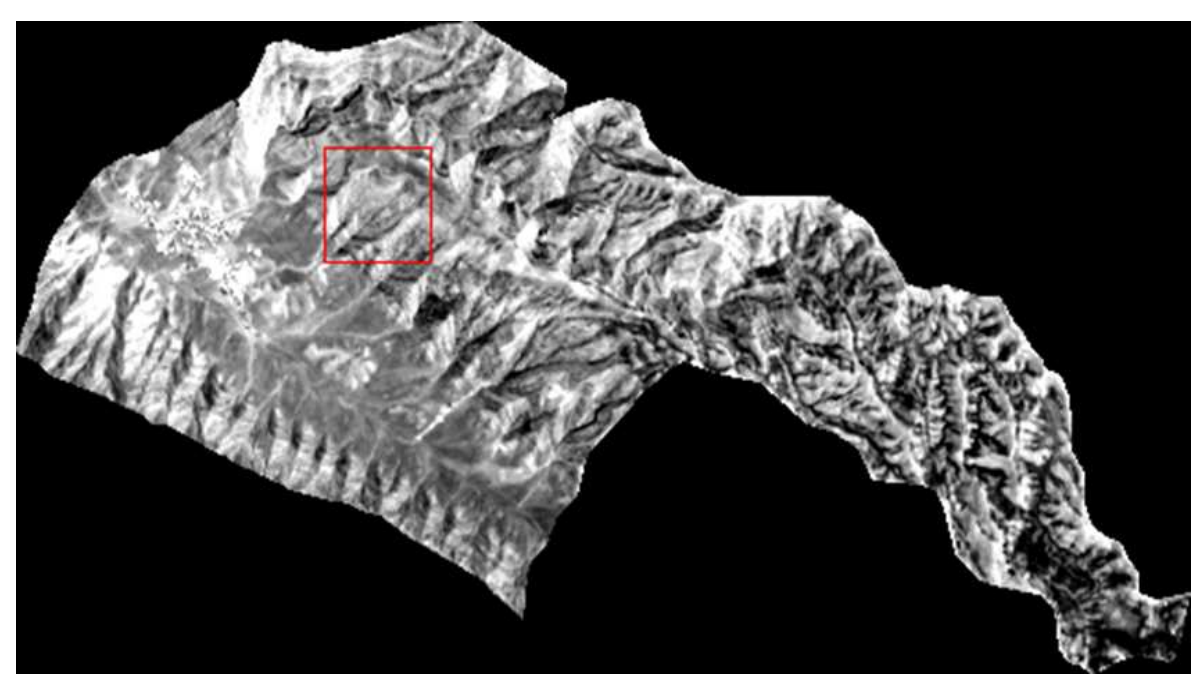

Fig. 6: View of the Landsat satellite in the Sardasht basin

\section{Evaluation of Classification Results}

Evaluation of classification results is one of the important steps after classification. The most commonly used method for quantitative evaluation is the accuracy of the classification of the use of known data (ground reality). The results of the accuracy assessment are presented as an error matrix, in which case a variety of parameters and values representing the accuracy or some kind of error in the results are extracted from this matrix. The error matrix is a comparison of the pixels with the corresponding pixels in the classification results. The basis of the error matrix is a number of parameters that are extracted to express accuracy, the most common are the overall accuracy and kappa coefficient.

\section{Classification Accuracy Assessment}

Evaluation of classification results is one of the important steps after classification. The most commonly used method for quantitative evaluation is the classification accuracy of the use of data (ground reality). The results of the accuracy assessment are presented as an Error Matrix, in which case a variety of parameters and values representing the accuracy or some kind of error in the results are extracted from this matrix. The error matrix is the comparison of the pixels with the corresponding pixels in the classification results.

\section{Pettitt Test}

The Pettitt Test is used to detect mutations in the mean value of data over time and is usually used in conjunction with the Mann-kendall Test. After the significance of the process is examined with this test at different levels, this test is used.

\section{Flow Duration Curve}

The Flow Duration Curve (FDC) is one of the valuable methods that display information from all flood runways. This curve shows the relationship between the discharge values and the percentage of time that this flow is equal to or greater than that. In other words, it shows the relationship between the magnitude and frequency of river discharge. To plot the flow continuity curve, we first arrange the flow rates of each station in descending order and show the probability of empirical occurrence of the y-axis and the probability of empirical occurrence obtained from the Weibull equation on the $\mathrm{X}$-axis.

Using this method, the statistics of the discharge of this basin are considered in the years before and after the construction of structures. In the Flow Duration Curve, discharge values are plotted for the prior and after watershed operations years. A comparison is made on a coordinate axis and any changes in the magnitude of floods with a return period, especially if there is no significant change in inputs to the watershed and in particular rainfall is concerned with watershed management.

\section{Hydraulic Regime}

In this method, it is possible to examine the status of the watershed outlet before and after the watershed operations in the basin. If there is a large difference between these two periods, one can find out the effect of the watershed operation. In this method, first, the monthly rainfall and runoff before and after the watershed are separated, then, using the ratio between each of the data to its average in the period considered, it is plotted. In this method, the status of the basin's outlet is evaluated in relation to its long-term mean values. 


\section{Land Use Classification by Maximum Likelihood Method}

The land use map derived from this method is as follows. A number of educational samples were taken to evaluate the classification accuracy, which results in the classification evaluation as an error matrix according to Table 2. Figure 7 shows the land use classification for 2014 in the Maximum Likelihood Method.

\section{Calibration and Validation of the SWAT Model}

Due to the fact that the Sardasht basin lacked a hydrometric station to simulate runoff and sediment, the nearest stations were used for calibration and validation. Calibration and validation of runoff and sediment and estimation of simulation accuracy estimated by SWAT model were first used for calibration and validation of Zarrin derakht hydrometric station information. The Zarrin derakht hydrometric station is part of the Lordegan sub-basin. SWAT-CUP software and SUFI-2 algorithm were used to calibrate the SWAT model.

In this research, simulation results were evaluated in the calibration and validation phases of the model with Coefficient of determination (R2), Nash-Sutcliffe (NS) indices. The Equation (1) of the mathematical equation shows the coefficient of explanation:

$$
R^{2}=\frac{\left[\sum_{i=1}^{n}\left(\text { Simulated }_{i}-\text { Simulated }_{\text {avg }}\right)\left(\text { Measured }_{i}-\text { Measured }_{\text {avg }}\right)^{2}\right]}{\sum_{i=1}^{n}\left(\text { Simulated }_{i}-\text { Simulated }_{\text {ovg }}\right)^{2} \sum_{i=1}^{n}\left(\text { Measured }_{i}-\text { Measured }_{\text {ovg }}\right)^{2}}
$$

\section{Where:}

Simulated $_{\text {avg }}=$ Average simulated values

Measured $_{\text {avg }}=$ Average measured values

The coefficient of determination represents a part of the total variance of the observed values, which is explained by simulated values. The Correlation coefficient shows that the regression line between predicted and observed values is close to the maximum level of coordination between these two series of values and varies from 0 to 1 . If the value of this coefficient is close to one, it is shown that the observational and simulation results are close to each other and the results are more favorable.

\section{Nash - Sutcliffe}

This method shows the relative difference between the observed and simulated values. It is calculated from Equation (2):

$$
E_{N S}=1-\frac{\sum_{i=1}^{n}\left(\text { Measured }_{i}-\text { Simulated }_{i}\right)^{2}}{\sum_{i=1}^{n}\left(\text { Measured }_{i}-\frac{1}{n} \sum_{i=1}^{n} \text { Measured }_{i}\right)^{2}}
$$

Table 2: Error Method of Maximum Likelihood Method

\begin{tabular}{ll}
\hline Kappa coefficient & Overall accuracy (percent) \\
\hline 0.74 & 83.55 \\
\hline
\end{tabular}

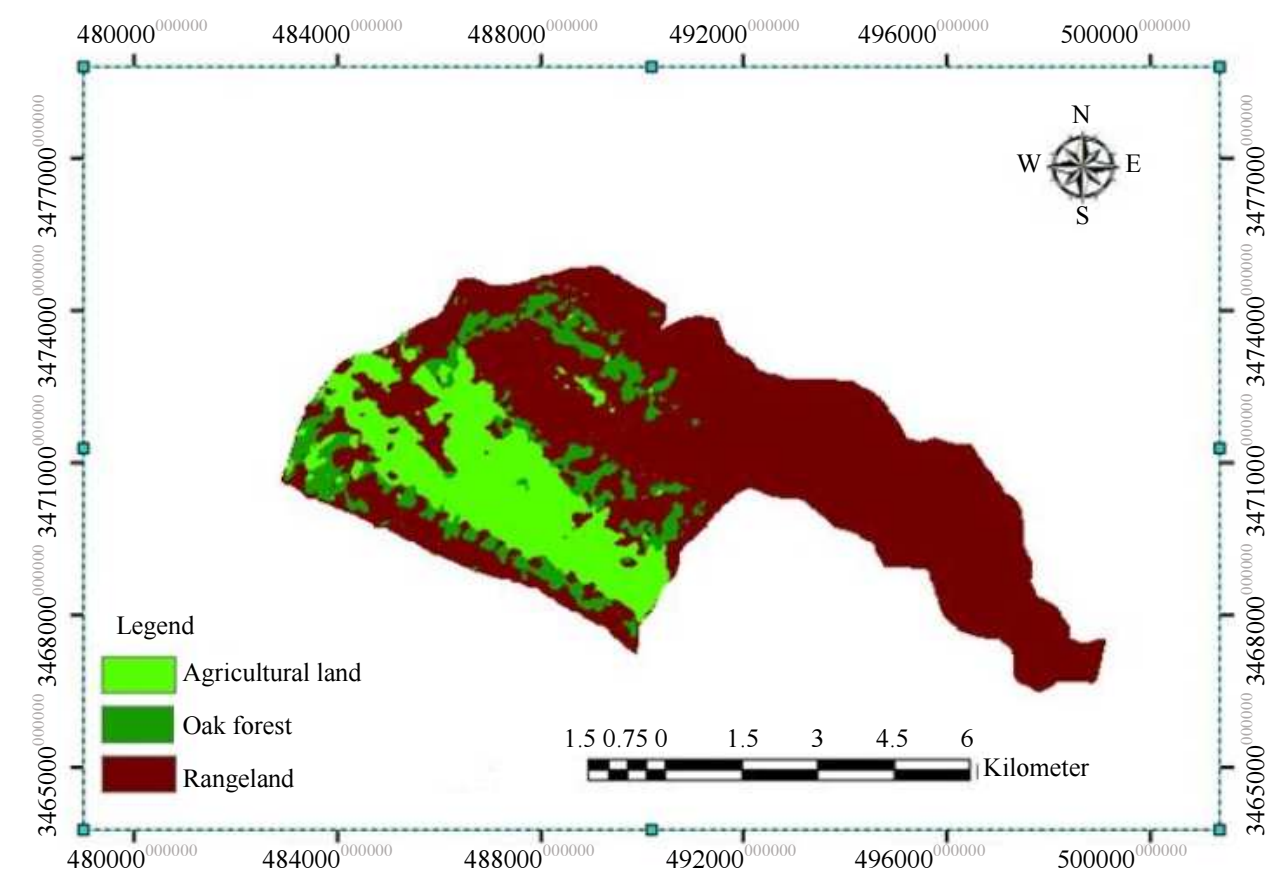

Fig. 7: Land use classification for 2014 in the maximum likelihood method 
The magnitude of the Nash-Sutcliffe coefficient changes from one to negative infinity. The optimal value of this coefficient is one. If the Nash-Sutcliffe coefficient is more than 0.75 , then the model is excellent and complete. If it is between 0.75 and 0.36 , the model is satisfactory and if it is less than 0.36 is considered unacceptable. Nash-Sutcliffe shows that the regression line between observed and predicted values is consistent with the regression line with slope 1 . The values between zero and one of these coefficients are acceptable as the level of performance. The values below zero indicate the level of performance unacceptable (Nash and Sutcliffe, 1970).

The statistical results of the runoff calibration period with R2 coefficient equal to 0.83 and Nash-Sutcliffe coefficient equal to 0.83 and the statistical results of runoff validation period with $\mathrm{R} 2$ coefficient equal to 0.76 and Nash-Sutcliffe coefficient equal to 0.44 . Calibration and validation results in runoff forecast are shown in Table 3.

Figures 7 and 8 show the calibration and validation of runoff at $95 \mathrm{ppu}$, which indicates the high accuracy of the model during calibration in the period of 2002-2011 and runoff validation during the period of 1996-2001. According to Table 4, sediment calibration was also carried out during the statistical period of 2002-2009 and validation in the period 1996-2001, which was similar to runoff simulation (Fig. 8 and 9). Therefore, it is possible to simulate runoff and sediment in the Sardasht basin.

\section{The length of the Main Streams}

The main stream refers to the waterway which runs on the talweg of the stream. It has the highest value in terms of length to the outlet point of the basin. The length of the main stream is influenced the time of concentration of the basin and also the time of the peak point flood discharge. The main stream length of Sardasht basin is $22.5 \mathrm{~km}$. Figure 10 shows the position of the main stream.

Table 3: Calibration and runoff validation in the SWAT model

\begin{tabular}{lll}
\hline Model Performance & $\mathrm{Ns}$ & $\mathrm{R}^{2}$ \\
\hline Calibration & 0.83 & 0.83 \\
Validation & 0.74 & 0.76 \\
\hline
\end{tabular}

Table 4: The amount of sediment and runoff simulated before the watershed operation

\begin{tabular}{lll}
\hline Year & Sediment (tons per hectare per year) & Runoff (cubic meters per second) \\
\hline 1996 & 19.56 & 0.45 \\
1997 & 14.35 & 0.46 \\
1998 & 22.95 & 0.61 \\
1999 & 20.2 & 0.53 \\
2000 & 6.96 & 0.16 \\
2001 & 17.53 & 0.38 \\
2002 & 13.35 & 0.44 \\
2003 & 21.87 & 0.57 \\
2004 & 22.94 & 0.58 \\
2005 & 26.95 & 0.70 \\
2006 & 39.24 & 0.83 \\
\hline
\end{tabular}

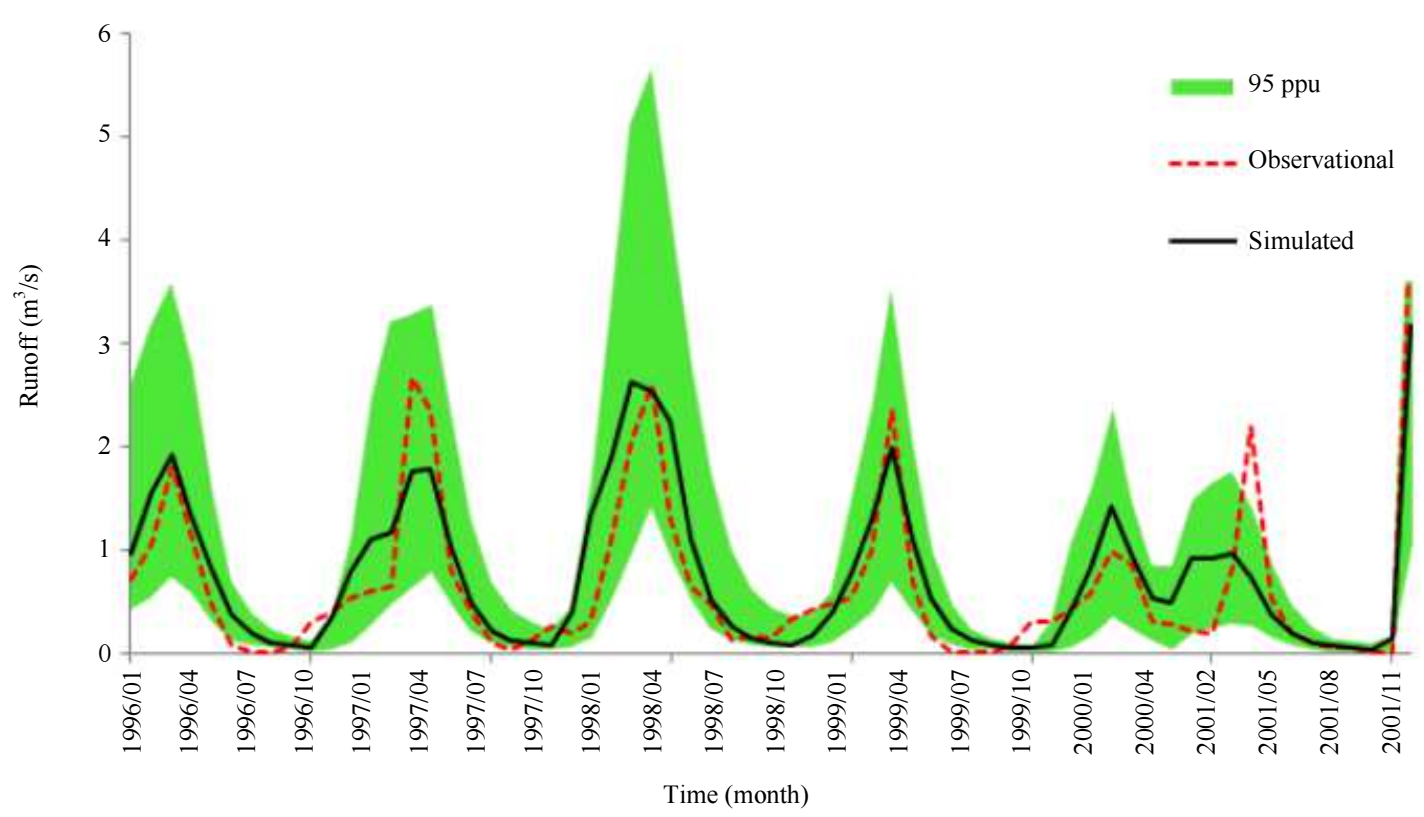

Fig. 8: Calibration of runoff in SWAT model using SWA-CUP 


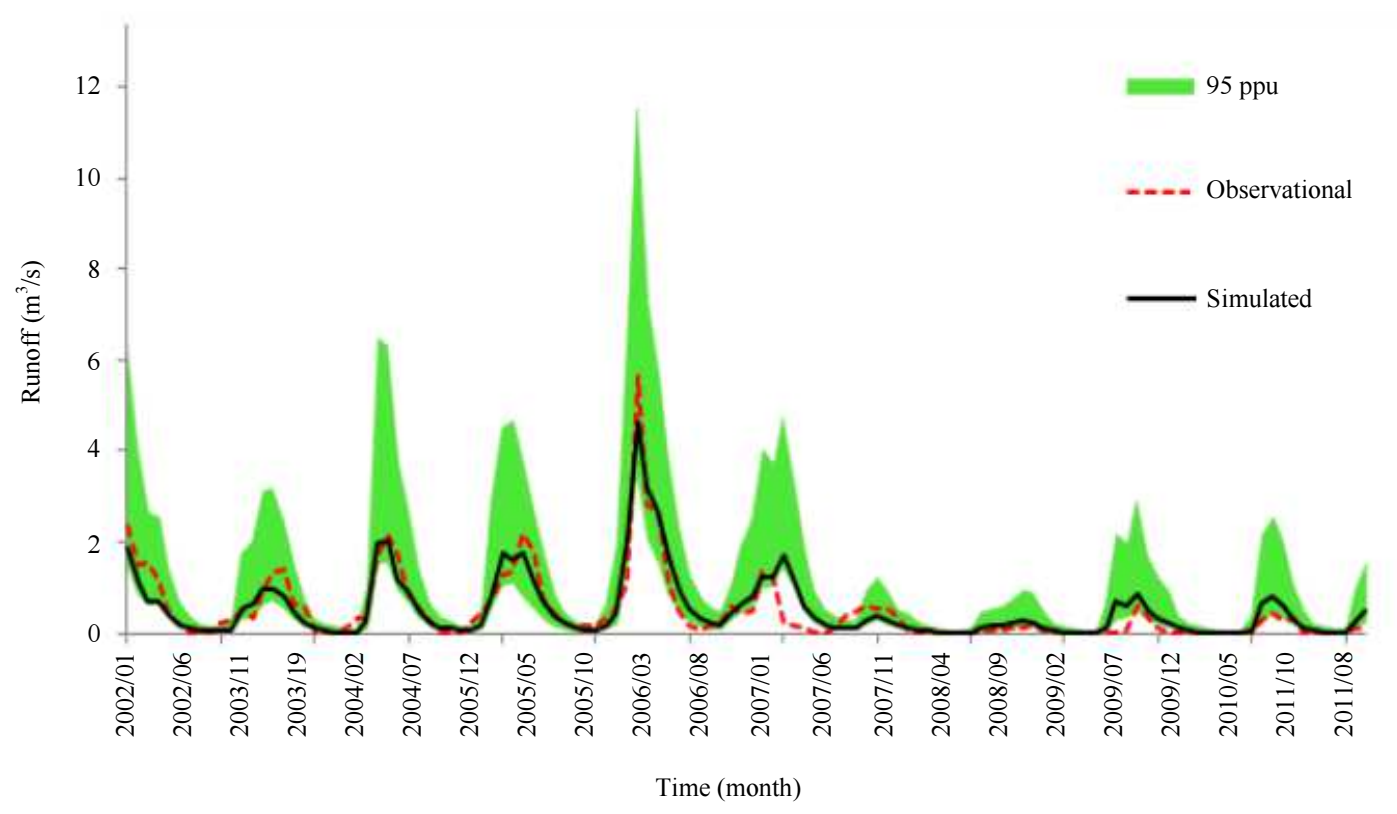

Fig. 9: Validation of runoff in SWAT model using SWA-CUP

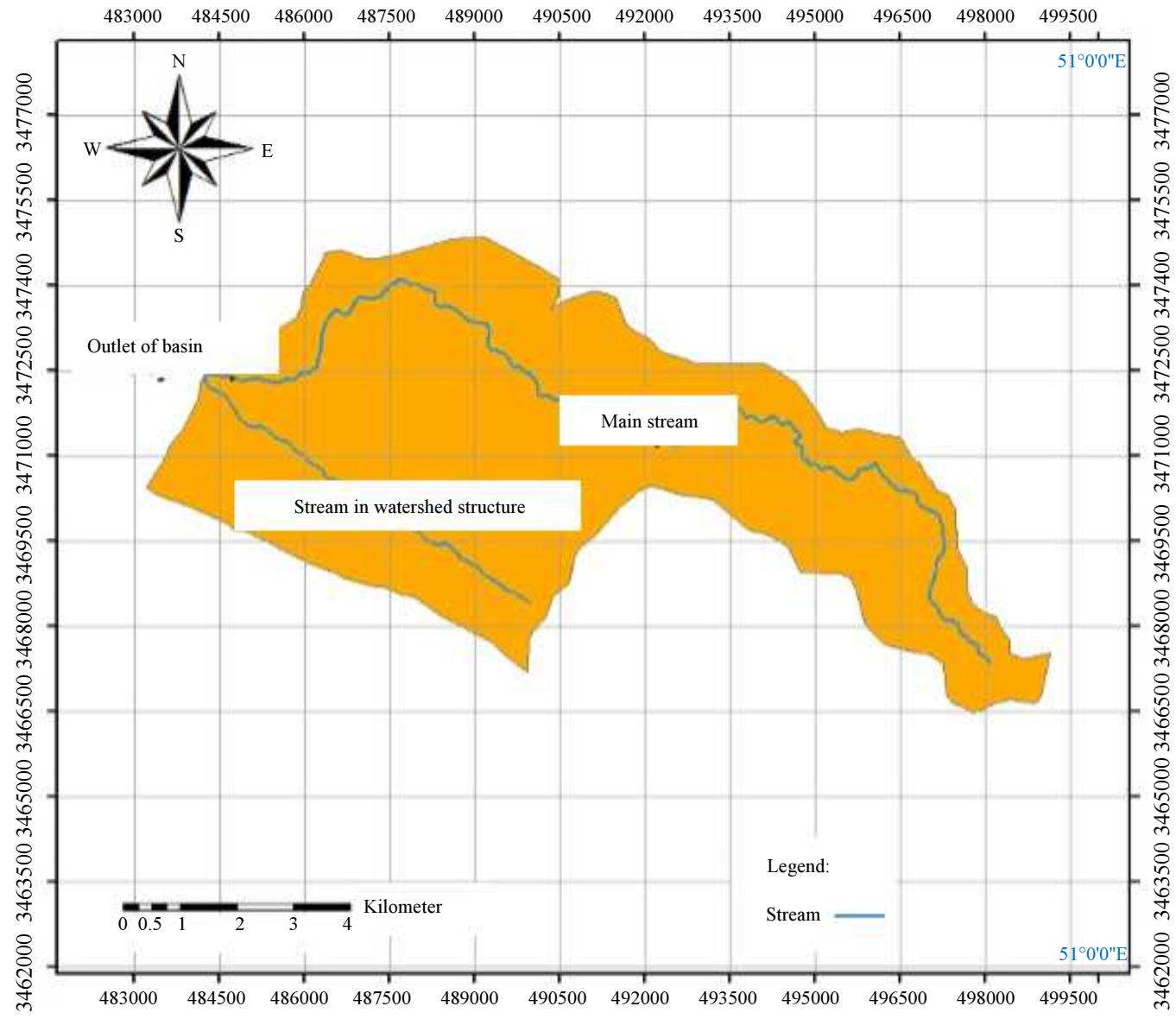

Fig. 10: Main stream of Sardasht basin 


\section{Results of the SWAT Model}

In order to investigate the performance of constructed structures in Sardasht basin, the SWAT model for runoff and sediment simulation during the studied period was carried out for 1996-2012 for two modes of existence and lack of flood control structures. The results of model implementation for these two modes are presented in Table 4. According to the collected data of the structures in 2007 and 2008, the results of model implementation and runoff simulation in accordance with Table 5 show this. To illustrate the details of Fig. 11 for monthly runoff simulation. As Fig. 12 shows, after the construction of flood control structures in the basin of peak discharge, has decreased, which indicates the positive effect of watershed operation in the basin. It shows Runoff differences before and after the watershed process after the creation of the constructions. In 2007 Runoff - before has the largest quantity and in 2010 runoff-after has the smallest quantity.

In order to investigate more precisely, the Sardasht basin is divided into three sub-basins. Therefore, the operation of Watershed in these two sub-basins is depicted in the following figures. Figures 13 and 14 show, respectively, sediment and runoff variations during the simulation period for subfields 1 and 3 . As these forms show, the sediment and runoff changes are the same and the amount of sediment has increased as the number of runoffs increases. The significant point in these forms is the state of sediment and runoff changes before and after the watershed operation.

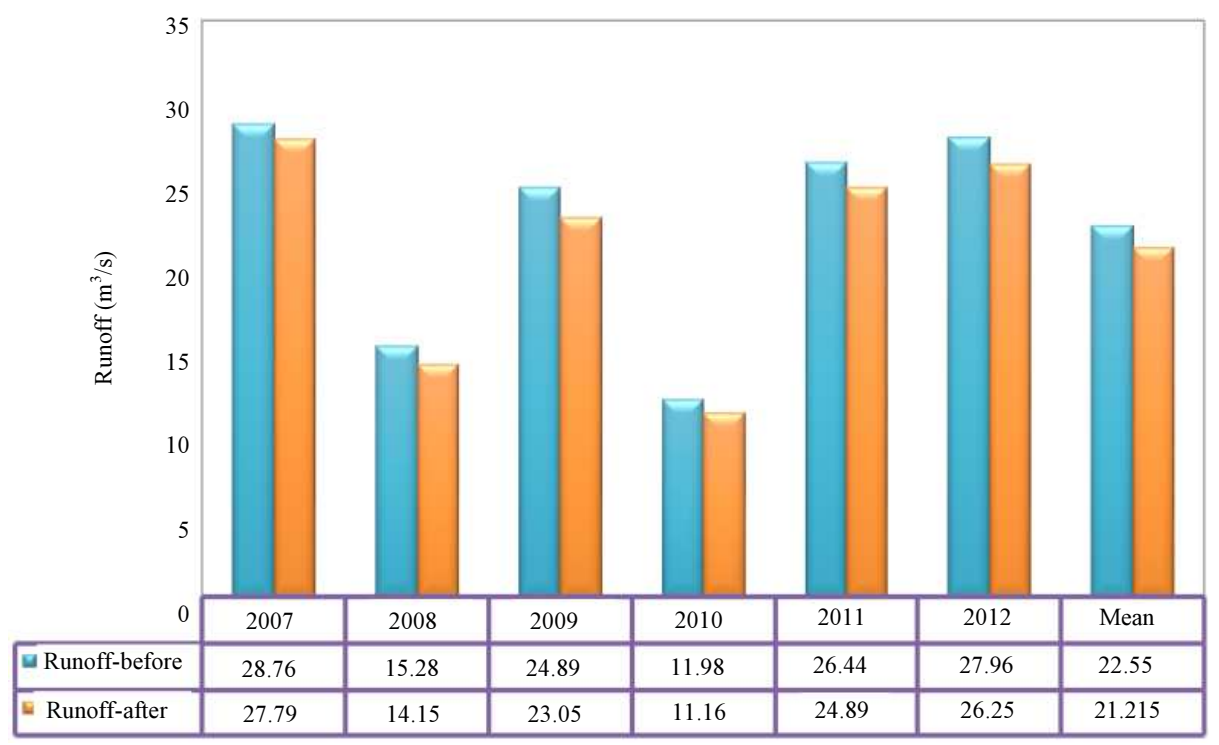

Fig. 11: Runoff variations before and after the watershed operation after the construction of the structures

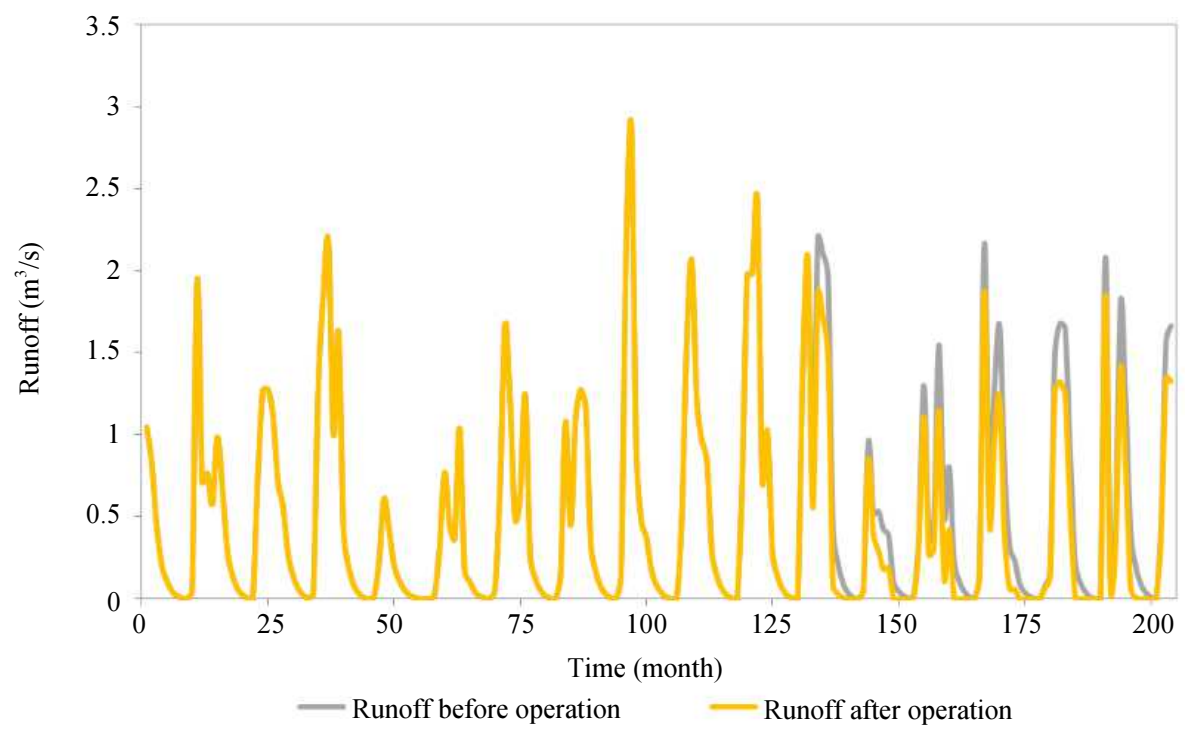

Fig. 12: Simulated monthly runoff before and after the watershed operation in Sardasht basin in 1992-1996 


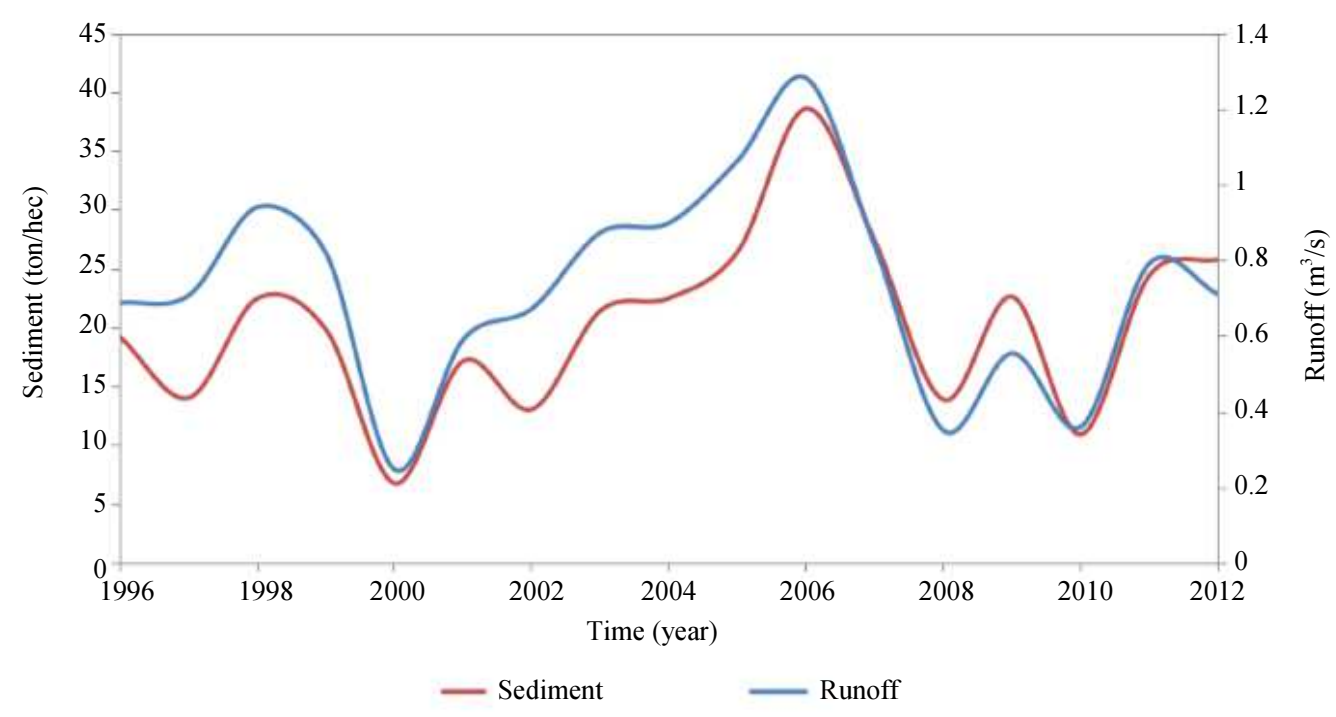

Fig. 13: Changes in annual precipitation and runoff in sub-basin 1

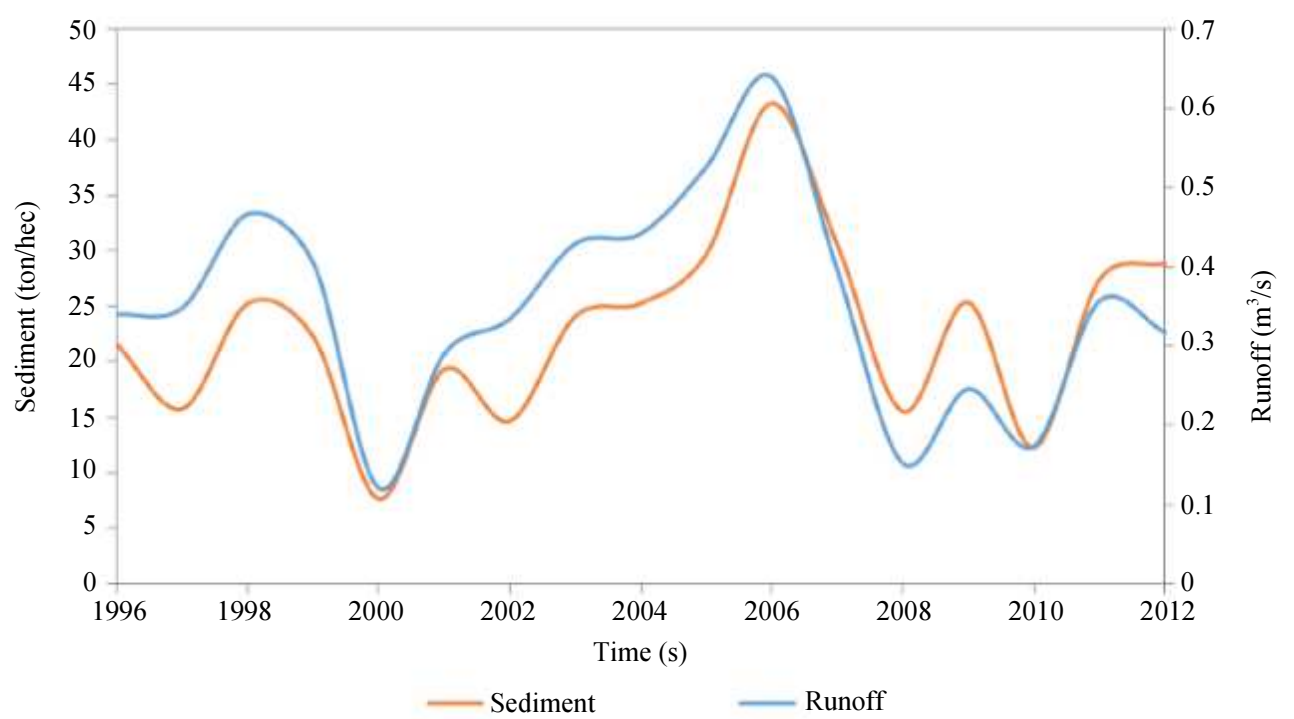

Fig. 14: Changes in annual precipitation and annual runoff in sub-basin

Table 5: Comparison of the amount of runoff changes after the construction of the structures

\begin{tabular}{lllll}
\hline Year & Runoff before operation & Runoff after operation & Amount of changes & Percent of reduction \\
\hline 2007 & 0.72 & 0.54 & 0.18 & 24.9 \\
2008 & 0.34 & 0.23 & 0.11 & 32.5 \\
2009 & 0.55 & 0.36 & 0.18 & 33.9 \\
2010 & 0.38 & 0.23 & 0.15 & 38.5 \\
2011 & 0.68 & 0.51 & 0.17 & 24.4 \\
2012 & 0.65 & 0.46 & 0.19 & 28.8 \\
Mean & 0.55 & 0.39 & 0.16 & 29.4 \\
\hline
\end{tabular}

According to the Fig. 13 and 14, the amount of sediment in the years prior to 2007 and 2008 is lower than the amount of runoff, but since the operation, this process has become more regular and with regard to runoff, sediment is controlled and runoff is lower than sediment. Figures 15 and 16 show the comparison of annual simulated runoff variations under sub-basin 1 and 3 before and after watershed operations. As these 
figures show, by performing watershed operations in these sub-basins, the average runoff rate from 2007 onwards decreased by about 250 lit/s for sub-basin 1 and $150 \mathrm{lit} / \mathrm{s}$ for sub-basin 3. This indicates flood has controlled in these basins.

For a more detailed study of sediment and runoff changes, it has been investigated monthly. Figures 17 and 18 show the simulated monthly runoff values for sub-basins 1 and 3, in the presence of flood control structures and the absence of these structures. As these figures show, after the watershed operation in the basin, the maximum amount of discharge has dropped below the basins. In other cases, the amount of runoff before and after the operation is almost unchanged. On average, the amount of runoff has decreased by 0.25 and $0.15 \mathrm{~m}^{3}$, respectively, under the basins 1 and 3 , in the presence of the structure in relation to the absence of structures.

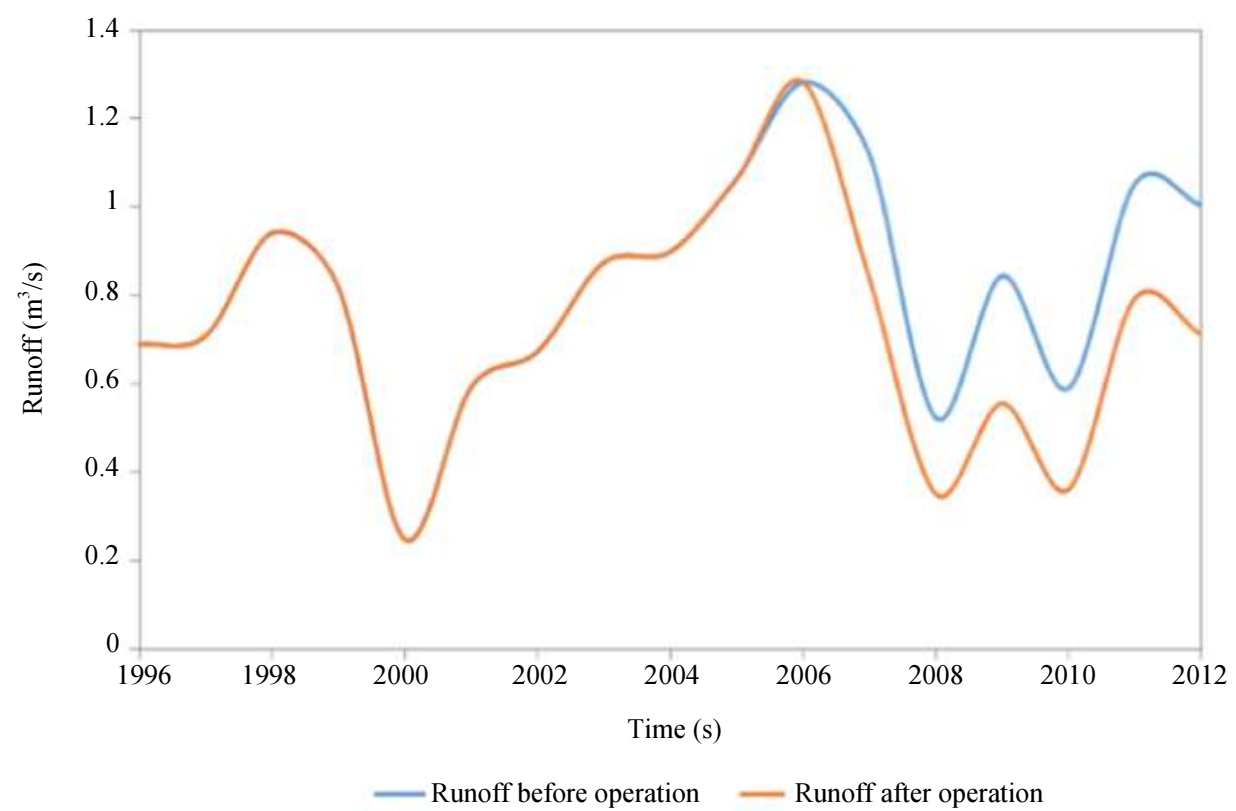

Fig. 15: Simulated annual runoff in sub-basin 1 during the years 1996-2012

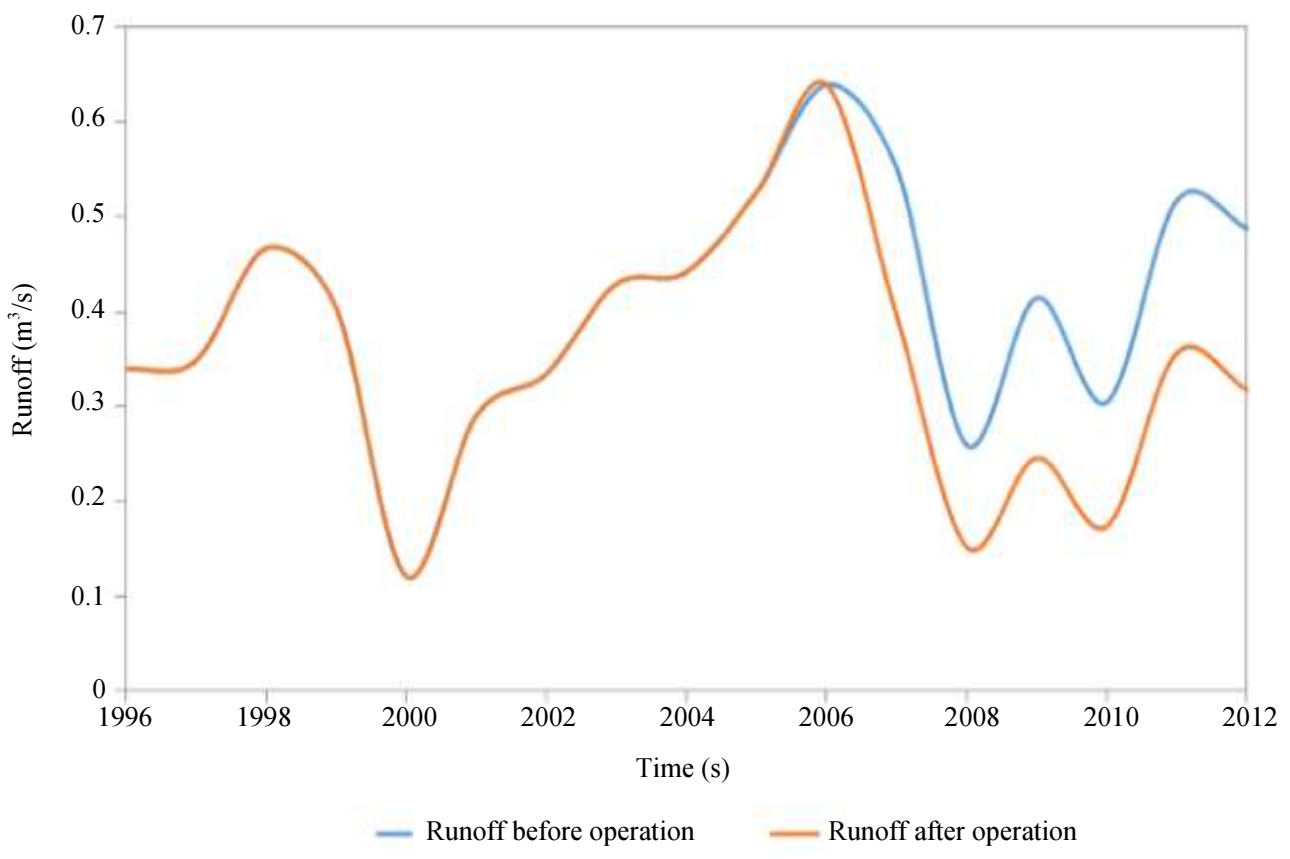

Fig. 16: Simulated annual runoff in sub-basin 3 during the years 1996-2012 


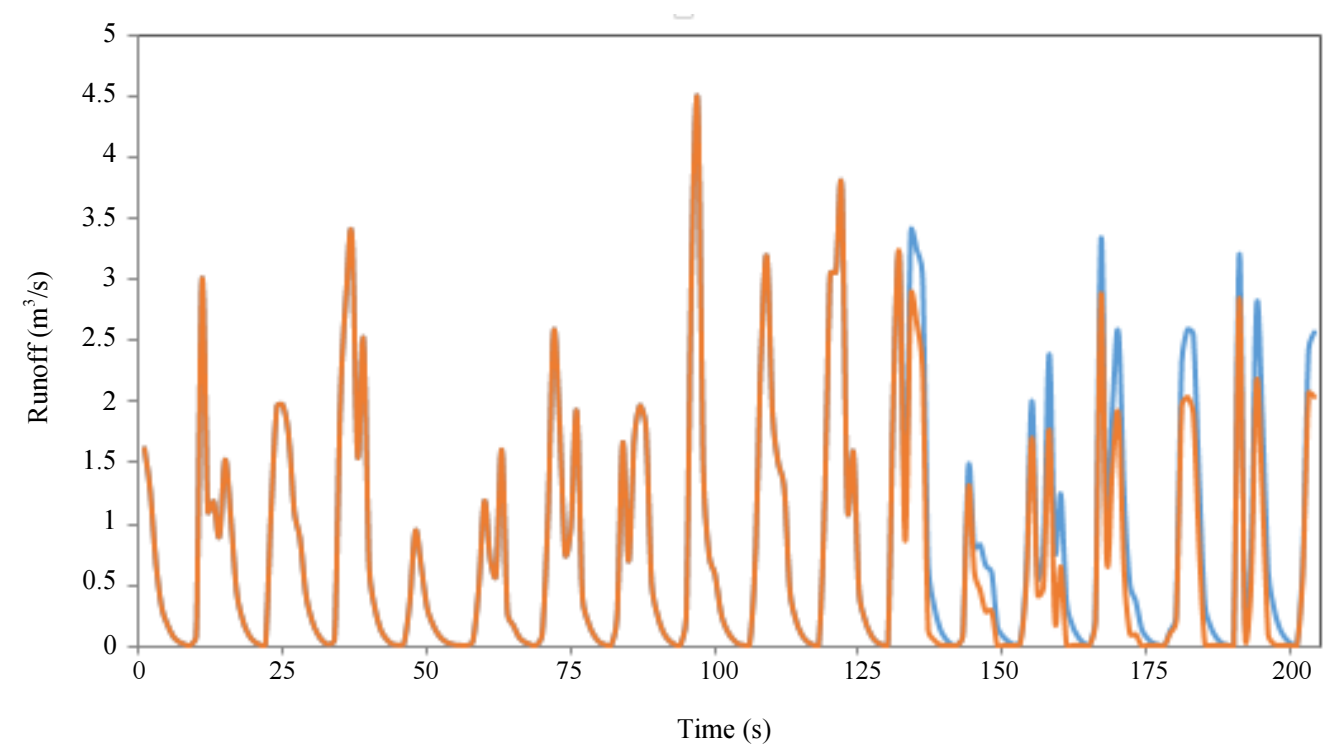

Runoff before operation $\quad$ Runoff after operation

Fig. 17: Simulated monthly runoff in sub-basin 1 during the years 1996-2012

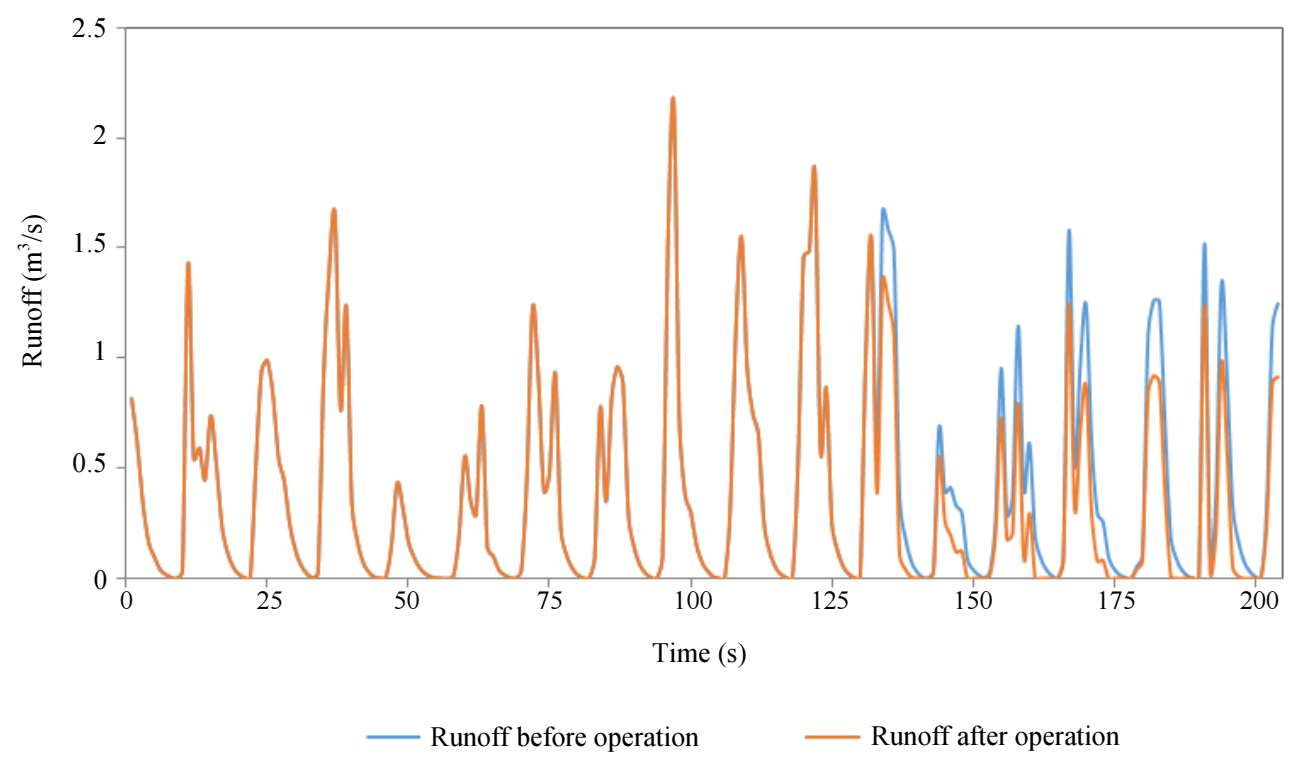

Fig. 18: Variations of simulated monthly runoff in sub-basin 3 during the years 1996-2012

\section{Investigate of Monthly flow Discharge}

In this study, the modified Mann-Kendall Test was used to study the trend of runoff data. After calculating the monthly data flow discharge for subbasins, the modified Mann-Kendall test results are shown in Table 6. As the results of this table show, there has been a significant trend in all of the subbasins and the sardasht basin in runoff amounts. However, no significant trend has been observed in sediment amounts. As the results of this table shows, sub-basin 1 trend at the probability level of $10 \%$ and sub-basin 3 trends at the 5\% probability level was significant. Table 6 data shows that watershed operation in sub-basin 3 has a better effect on runoff. However, the amount of sediment in sub-basin 1 was more in control. In general, according to the results of the Mann-Kendall Test, Watershed management in the Sardasht basin for flood sediment and runoff can be evaluated as acceptable. 


\section{Study of Flow Duration Curve}

Another application in the field of assessing watershed operation in the basin is Flow Duration Curve. For this purpose, the Flow Duration Curve was plotted before and after the watershed. Figures 19 to 21, respectively, relate to the continuity curves of sub-basin 1,3 and the whole basin. It can be deduced from the study of the curves presented in these forms before and after the watershed measures that, before the occurrence of the actions, the likelihood of occurrence of high flood occurrence in the basin is greater than after the operation. This shows the greater likelihood of a flood event before the watershed operations than after the watershed operations.

Table 6: Characteristics of $Z$ and the slope of the Mannkendall Test process for runoff and sediment

\begin{tabular}{llll}
\hline Number of sub-basins & Parameter & $\mathrm{Z}$ & Slope \\
\hline Sub-basin 1 & Runoff & -1.776 & -0.0004 \\
& Runoff & -1.05 & -0.0059 \\
Sub-basin 3 & Runoff & -1.962 & -0.00028 \\
Whole of basin & Sediment & -0.7 & -0.000013 \\
& Runoff & -1.814 & -0.00025 \\
& Sediment & -1.06 & -0.0058 \\
\hline
\end{tabular}

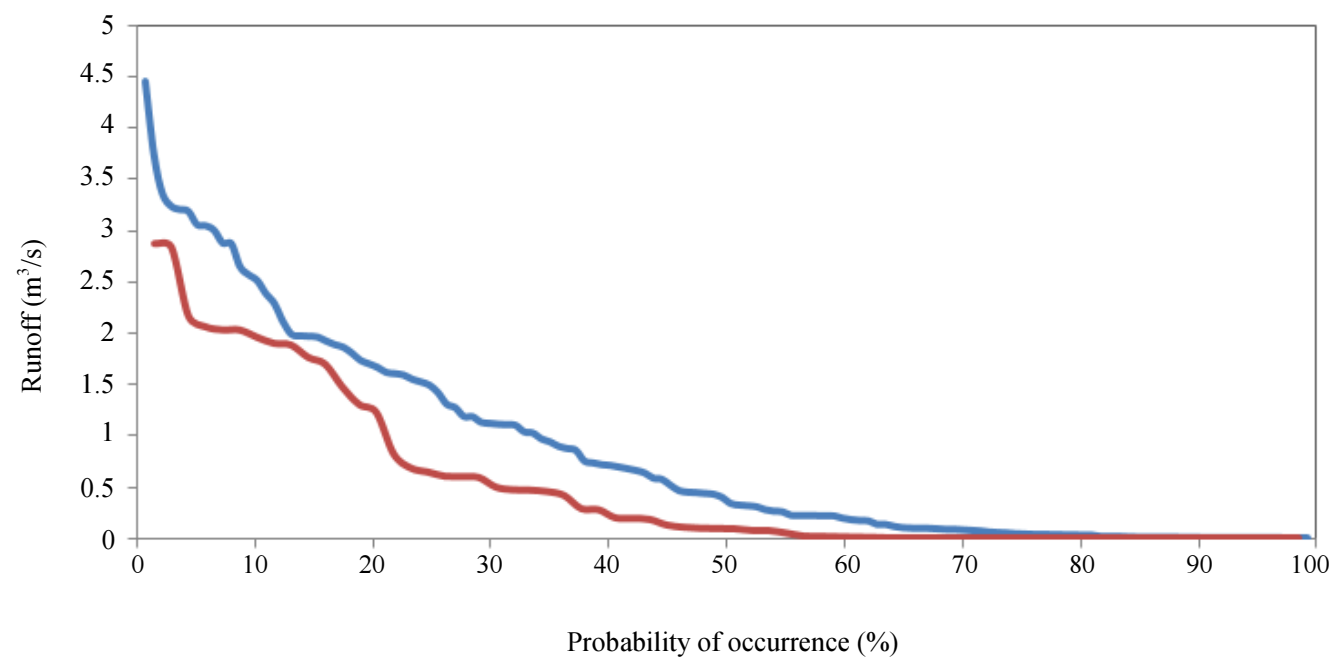

PDF before operation

PDF after operation

Fig. 19: Comparison of the flow duration curve before and after watershed operations in the sub-basin 1

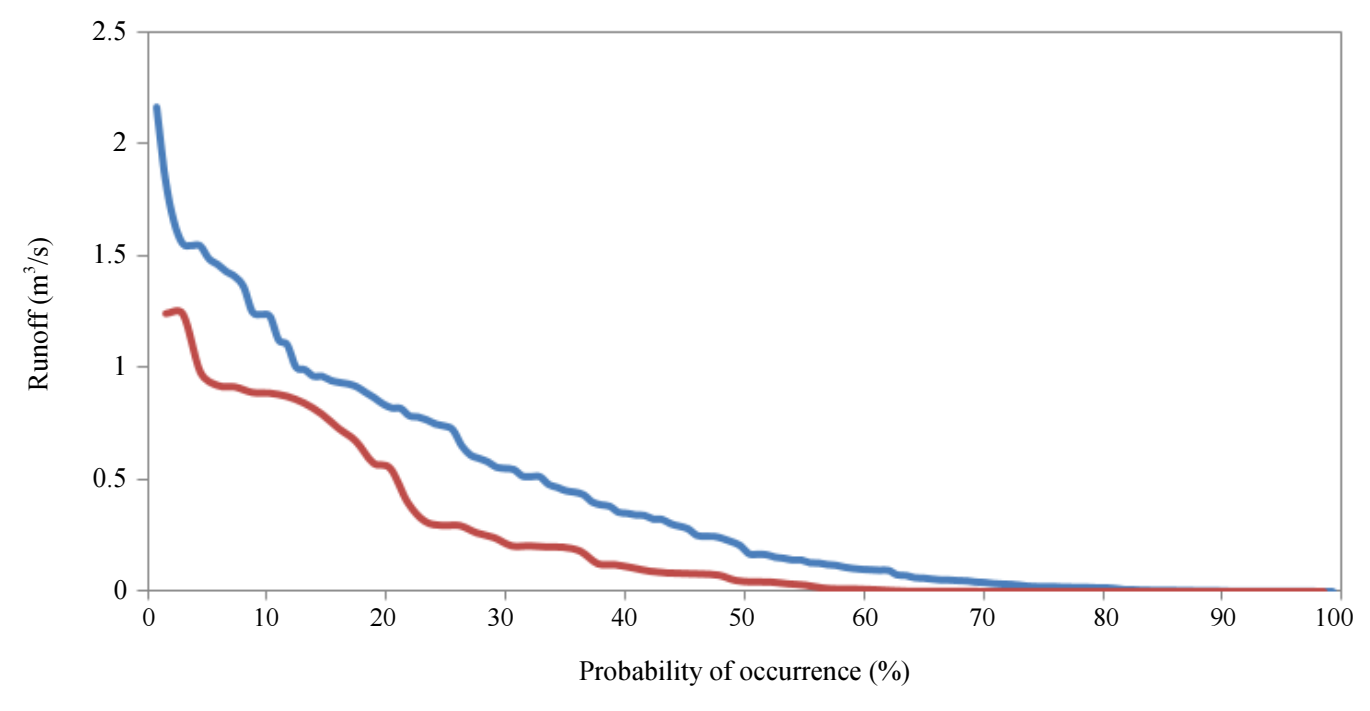

PDF before operation

PDF after operation

Fig. 20: Comparison of the flow duration curve before and after watershed operations in the sub-basin3 


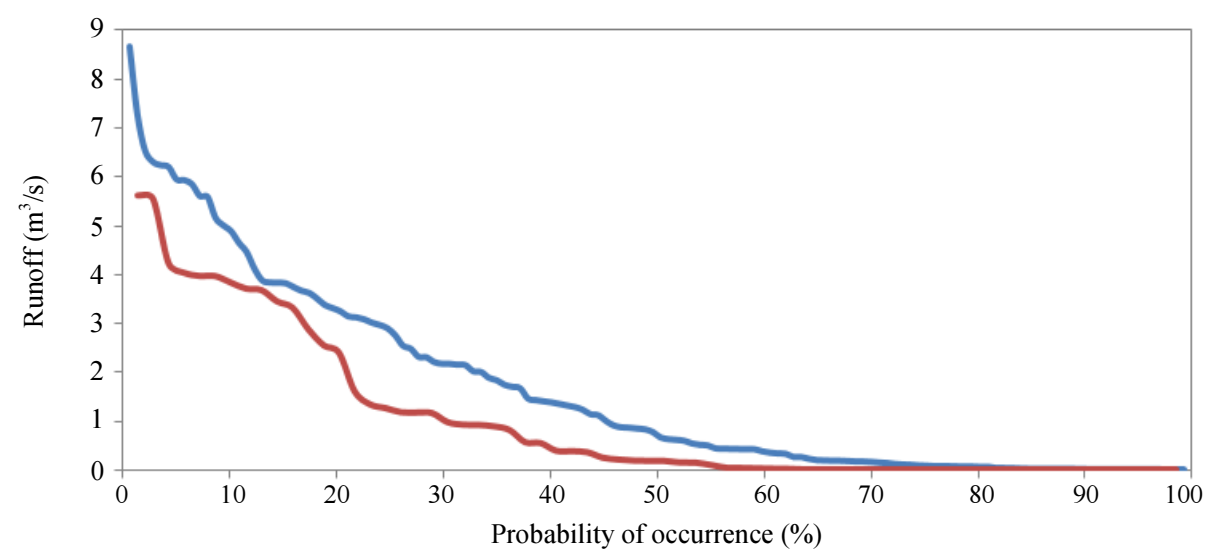

PDF before operation _ PDF after operation

Fig. 21: Comparison of the flow duration curve before and after watershed operations in the whole basin

Table 7: Runoff values for different return periods in Sardasht sub-basins $\left(\mathrm{m}^{3}\right)$

\begin{tabular}{|c|c|c|c|c|c|c|}
\hline \multicolumn{2}{|l|}{ Whole of Basin } & \multicolumn{2}{|l|}{ Sub-basin 3} & \multicolumn{2}{|l|}{ Sub-basin 1} & \multirow[b]{2}{*}{$\begin{array}{l}\text { Number of sub-basins } \\
\text { return period (Year) }\end{array}$} \\
\hline $\begin{array}{l}\text { After watershed } \\
\text { operation }\end{array}$ & $\begin{array}{l}\text { Before watershed } \\
\text { operation }\end{array}$ & $\begin{array}{l}\text { After watershed } \\
\text { operation }\end{array}$ & $\begin{array}{l}\text { Before watershed } \\
\text { operation }\end{array}$ & $\begin{array}{l}\text { After watershed } \\
\text { operation }\end{array}$ & $\begin{array}{l}\text { Before watershed } \\
\text { operation }\end{array}$ & \\
\hline 0.172 & 0.65 & 0.043 & 0.17 & 0.08 & 0.33 & 2 \\
\hline 2.39 & 3.23 & 0.550 & 0.82 & 1.23 & 1.66 & 5 \\
\hline 3.83 & 4.88 & 0.890 & 1.23 & 1.96 & 2.51 & 10 \\
\hline 4.035 & 5.94 & 0.920 & 1.48 & 2.05 & 3.05 & 20 \\
\hline 5.55 & 6.51 & 1.240 & 1.65 & 2.84 & 3.35 & 50 \\
\hline 5.62 & 7.27 & 1.243 & 1.81 & 2.88 & 3.74 & 100 \\
\hline
\end{tabular}

The results obtained in this section, in addition to confirming the positive performance of watershed operations in the Sardasht basin, confirm the ability of the Flow Duration Curve (FDC) method in quantitative analysis of hydrological events in different periods. Table 7 shows the amount of runoff in each sub-basin and the whole basin for the period of returns before and after the watershed operation. Comparison of the values of the discharge before and after the operations showed that after the measures compared to the previous ones, the runoff values for the different return periods had a decreasing trend. As these figures show, before the watershed operation, the occurrence of runoff with the probability of $80 \%$ is zero, after which the amount of this value is reduced to a probability of $60 \%$, which indicates the positive effect of constructing flood control and sediment control structures in the Sardasht basin.

\section{Results of Pettitt Test}

After using the Pettitt Test, the runoff data was calculated in sub-basins 1 and 3 . The results of this test are shown in Table 8 . The results of this test are shown in Table 8. As the results show, after the watershed operation in Sardasht watershed, deflated runoff amounts were created and average monthly runoff values decreased after the operation, indicating the proper operation of the structures in runoff control. In general, runoff has decreased by an average of $0.6 \mathrm{~m}^{3}$ in the whole basin after the watershed operation.

In order to evaluate the performance of the watershed operation in the watershed basin, the results of the Pettitt test are shown in the following figures. Figures 22 to 24 respectively show the results of the Pettitt Test for subbasins 1, 3 and the whole basin. Dashed lines in these charts show the average monthly runoff before and after the breakpoint (the turning point).

Hydrological regime curve results One of the methods used for the performance of the watershed operation in a basin is to study the hydrological regime curves. Figure 25 shows the hydrological regime curve of Sardasht watershed. The results of this figure indicate that changes in the monthly runoff ratio to the monthly average runoff before the watersheds are greater. After the watershed management, this turmoil has decreased. This indicates the trend of runoff production towards a natural equilibrium. Also, by comparing runoff ratios with monthly runoff average after the watershed operation, there is a point that the rainfall ratio is equal to the average monthly precipitation before the measures. However, its runoff is less and confirms the decreasing trend of monthly runoff in Sardasht basin. This indicates the positive effect of watershed management in this basin. In other words, the hydrologic response of the watershed after the operations. 


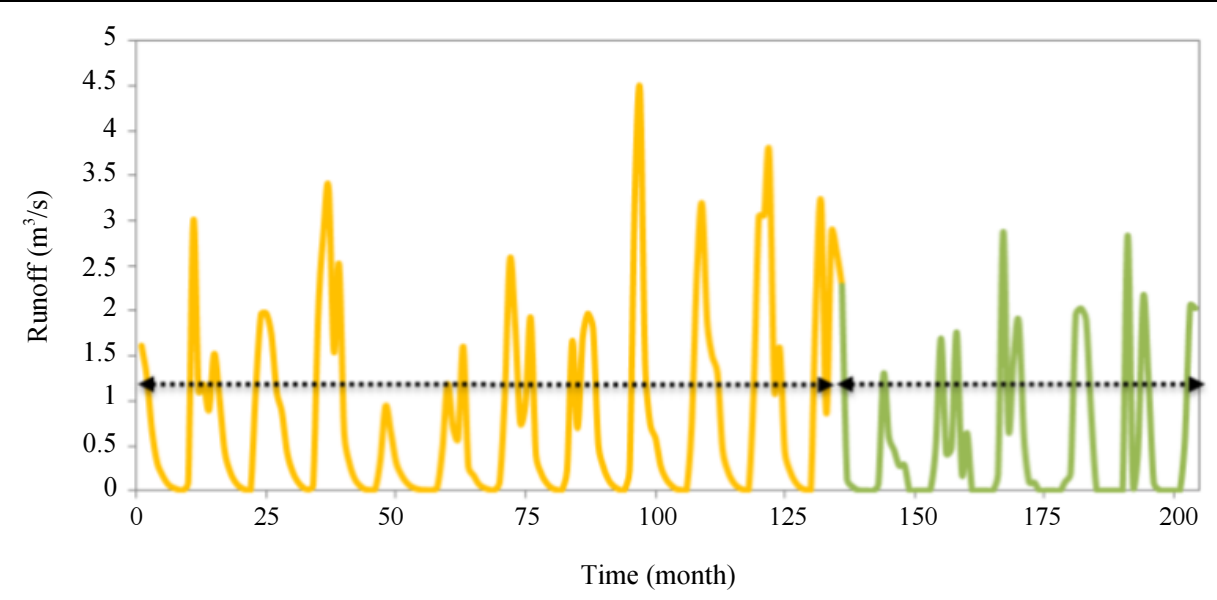

Before operation

After operation

Fig. 22: Pettitt test chart for runoff in sub-basin 1 during the years 1996-2012

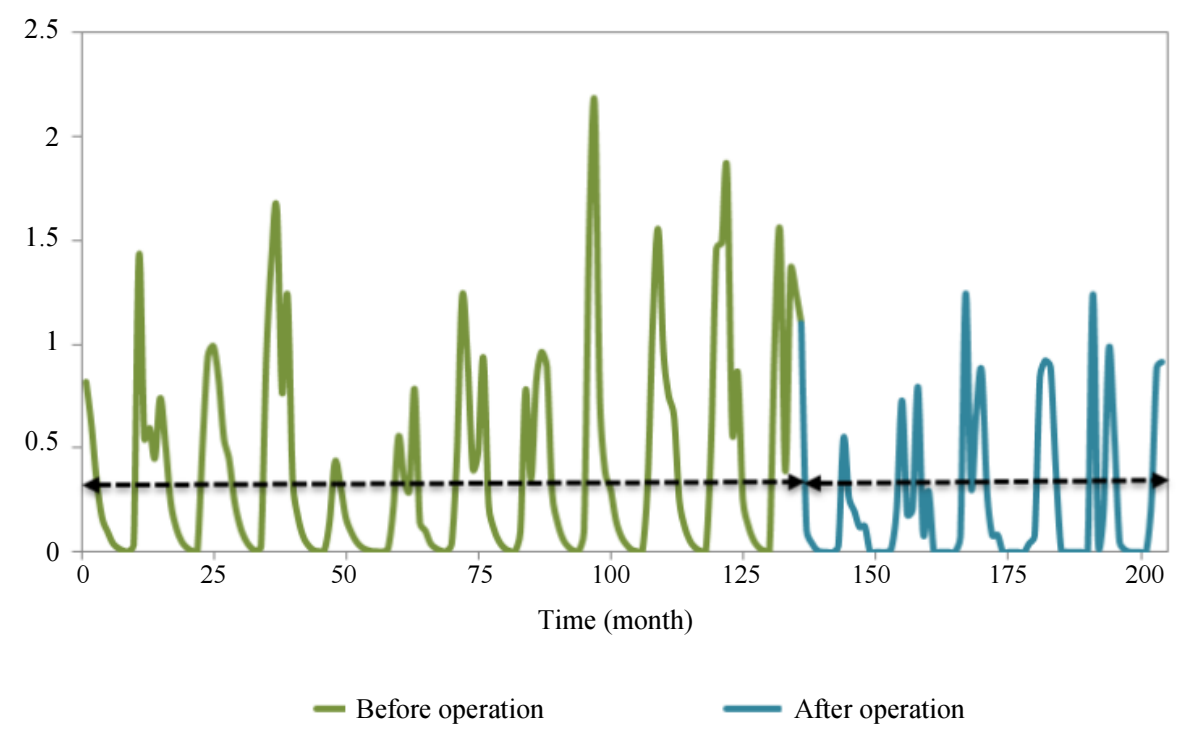

Fig. 23: Pettitt test chart for runoff in sub-basin 3 during the years 1996-2012

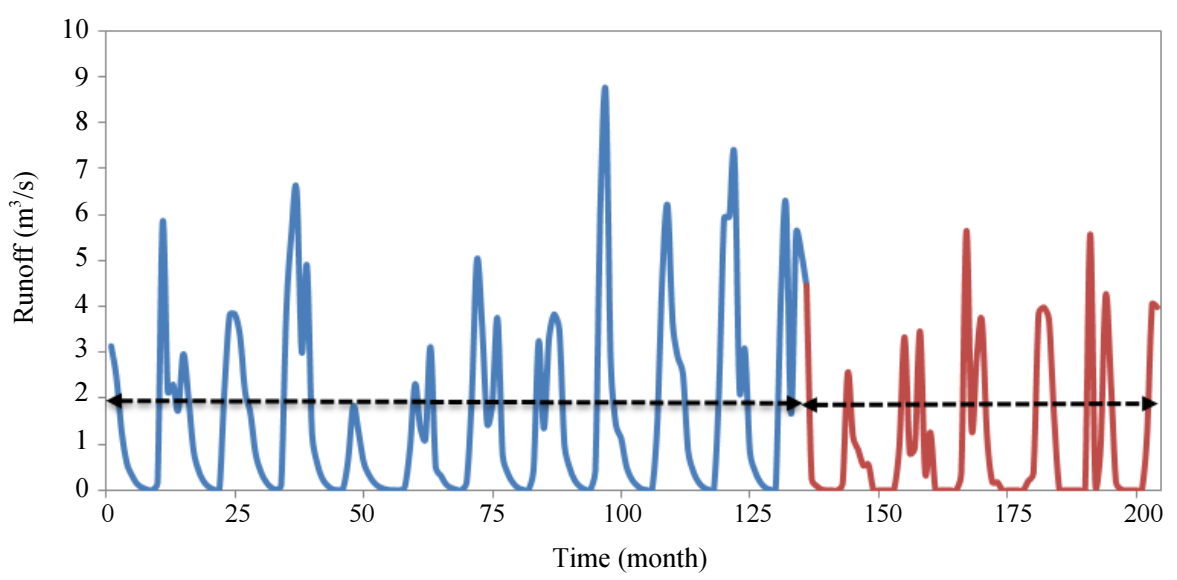

Before operation $\quad$ After operation

Fig. 24: Pettitt test chart for runoff in whole basin during the years 1996-2012 


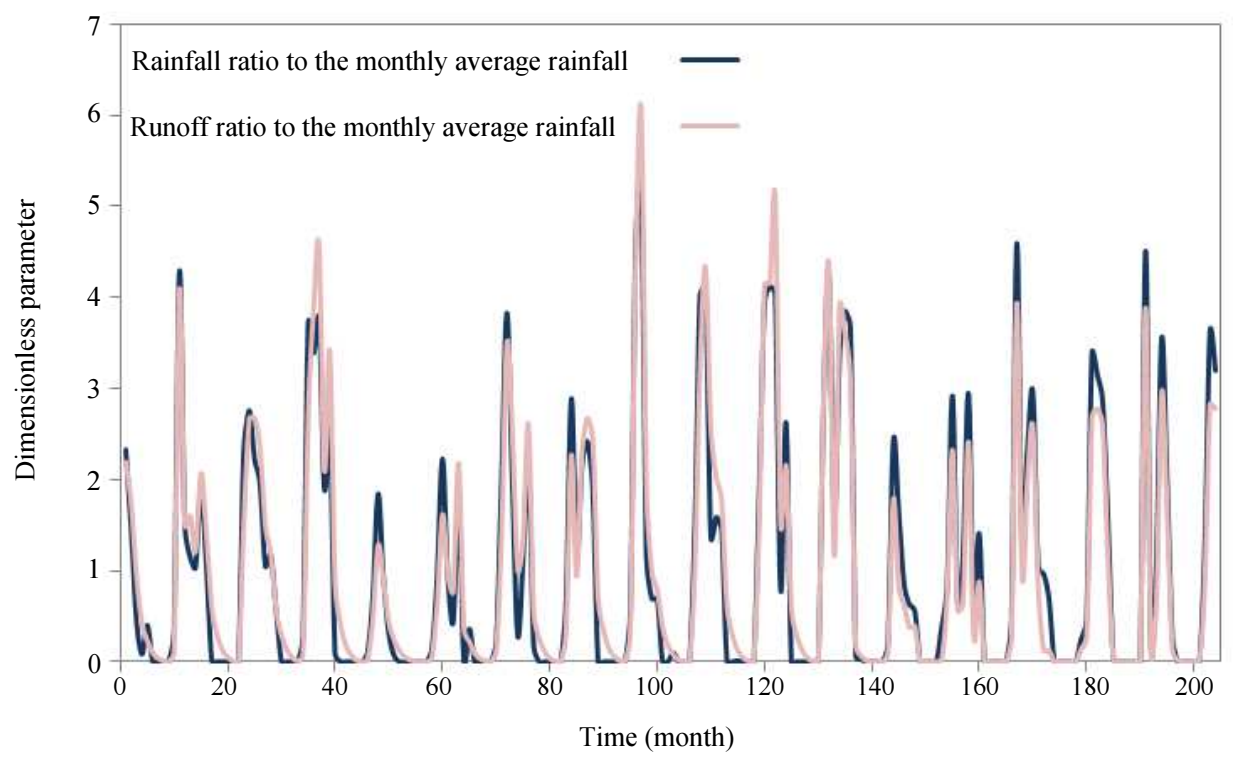

Fig. 25: hydrological regime with rainfall before and after the watershed management

Table 8: Results of the Break point of Pettitt Test for runoff during the years 1996-2012

\begin{tabular}{llll}
\hline Whole of Basin & sub-basin 3 & Sub-basin 1 & Number of sub-basins \\
\hline 4.49 & 1.1 & 2.58 & The Break Point \\
2007 & 2007 & 2007 & The year of Break Point \\
1.62 & 0.41 & 0.84 & Mean before \\
1.02 & 0.24 & 0.54 & Mean after \\
0.6 & 0.17 & 0.3 & Difference \\
\hline
\end{tabular}

\section{Results}

In over-all, the consequences displayed that SWAT could be an appropriate instrument for simulating runoff, sediment profit and nitrate loss into the river. The MannKendall assessment has been extensively applied to notice inclinations in agro-meteorological in addition to hydrological period sequence. It is obvious that 4 important factors are essential such as National plan, Watershed Management Projects, Watershed Management Practice, Watershed Management Activity. The position of structures is a crucial role for SWAT model.it is also noticed the sedimentary rock dams for regulating of flood. There are several criterions in subbasin for instance height, slope, area. Land use classification affects in result of the model. Ns and R2 for both calibration and validation are almost equal and has an appropriate result. In 2006, the quantity has the largest sediment and runoff simulated before the watershed operation. It is obvious that there is a little difference between runoff alteration before and after watershed process after the construction of the structures. Runoff before process rather than after process has a more quantity runoff that the most amount of changes between them is 0.19 in 2012 and the most percentage of reduction is 33.9 in 2009.
The results of the modified Mann-Kendall Test in Table 6 show that there was a significant trend in all subbasins and the whole basin in runoff values, but no significant trend was observed in sediment values. As the results of Table 6 show, sub-basin 1 trend at $10 \%$ probability level and sub-basin 3 trends at $5 \%$ probability level, which indicates a better effect of watershed management in sub-basin 3 on runoff. But the amount of sediment in sub- basin 1 has more control. The results of the Pettitt Test in Table 8 indicate that after the watershed operation in Sardasht watershed in the amount of runoff generated failure. The average monthly runoff values after the operation have been decreased, which indicates the proper performance of the structures in runoff control.

In general, runoff has decreased by an average of 0.6 $\mathrm{m}^{3} / \mathrm{s}$ in the whole basin after the watershed operation. In general, according to the results of the Mann-Kendall Test, Watershed management in the Sardasht basin for flood control and runoff can be evaluated as acceptable. The results of Fig. 25 of the hydrological curve of Sardasht watershed show that monthly runoff ratio changes to monthly average runoff before the measurements were lower and after the actions of this disorder decreased. Also, by comparing runoff ratios with monthly runoff average after the watershed 
operation, it is observed that the ratio of rainfall to average monthly rainfall is equal. But its runoff is less and it confirms the decreasing trend of monthly runoff in Sardasht watershed. Till be more detailed, the Sardasht basin is separated into three sub-basins that the constructions built for watershed operation are placed in the initial and third sub-basins. This shows the sill was inspected in these basins. On a mean, the runoff volume has reduced by 0.25 and $0.15 \mathrm{~m}^{3}$ in the subbasins 1 and 3 severally in the attendance of the structure contrasted to the deficiency of constructions. regard the consequences of the Mann-Kendall experiment, Watershed administration in the Sardasht basin for flood management and runoff can be examined allowable. As well as, it is noticed that almost rainfall proportion to monthly rainfall before the performances was the same, but there was a less generative runoff. It affirms the reducing trend of Sardasht's monthly runoff. Gathering rainwater applying procedures and ways in arid and semi-arid basins to prepare more water for agronomic, drinking and industry are named water expressing. Herb growth in the soil and water assessment tool is an evaluative procedure for the modality of the eco-hydrological pattern. It is confirmed by components like evaporation, soil erosion, etc. owing to the restrictions, modern SWAT simulations in tropical and subtropical zones encounter a system of issues linked to moderate humidity, water balance and sediment. The SWAT pattern is also applied to assess the most daily flow measurement.

\section{Discussion}

The incidence of aridities and unforeseeable sills in various sections of IRAN, also the compression on intrinsic facilities affected by crowd development, has due to a wider variation in consideration to the problem of water directly in the association. Watershed direction is a natural process that procedures, performances and directs plans. It designs for preserving, reproducing, expanding and utilizing optimum from renovating normal supplies in the water basins. The available description is essentially an evaluation of the watershed direction made in Sardasht water basin in Chaharmahal and Bakhtiari province. The consequences of this investigation can be applied to describe the zonal organization procedures, with an assertion on the key of flood rein shapes and the restriction of water and soil facilities in defining the applies and proceedings. In universal, the kind and measure of loading on the investigation basin. The procedure depends on ground performances and the record of the place and physical features of the built constructions. At initial, the essential and required data was prepared and the precision and reliability of the accounts were reconsidered. The precipitation was computed applying the procedure of co-ordinated lines. Then runoff from rainfall was accomplished relevant to the physical features of the basin. Then the runoff created before and after the landmark performance. To consider the proficiency of built constructions in Sardasht watershed, SWAT pattern for imagery of runoff and sediment during the work time of 1996-2012 was performed for two occasions of quality and lack of flood control constructions. Swat pattern analogizes the variable flow proficiency. The present report is basically an assessment of the watershed management performed in Sardasht watershed in Chaharmahal and Bakhtiari province. The study basin of Sardasht is part of the Karoon River basin, which consists of three sub-basins. The Pettitt test is used to detect mutations in the mean value of data over time and is usually used in conjunction with the Mann-Kendall test. This indicates the positive impact of watershed management in this basin. In other words, the hydrologic response is appropriate after the watershed operations.

\section{Conclusion}

Results of the SWAT model indicates after the construction of flood control structures in the basin of peak discharge has decreased, which indicates the positive effect of watershed operation in the basin. Results of Pettitt Test show that after the watershed operation in Sardasht watershed, deflated runoff amounts were created and average monthly runoff values decreased after the operation, indicating the proper operation of the structures in runoff control. In general, runoff has decreased by an average of $0.6 \mathrm{~m}^{3}$ in the whole basin after the watershed operation. The results of the modified Mann-Kendall Test shows that after the watershed operation in Sardasht watershed in the amount of runoff generated failure. In general, runoff has decreased by an average of $0.6 \mathrm{~m}^{3} / \mathrm{s}$ in the whole basin after the watershed operation. Weather condition variation and anthropological actions are the two main powerful components that impact the hydrological series and Runoff Controlling. The watershed features component depicted the main pattern, which shows that runoff mutability is most susceptible to zone area variations owing to plants alteration and land application and land cover alteration. Weather condition alterations have meaningfully changed the land-water series. Differences in weather condition straight change the hydrological procedures, containing rainfall, evaporation and the land-surface hydrological cycle which impact runoff. Hydrological procedures in an assorted land usage watershed are meaningfully inclined by land usage and land protection. Measured and model-simulated evaluates of runoff profit from various sub-watersheds were employed to prioritize control procedures in the watershed including zones under agriculture, waste, unplanted and eroded land and forest and bushes. 
Computational numerical approaches often create the regression association between the runoff and climatic aspects but it is hard for this technique to clarify the physical instrument behind the variations. In the new year, under the circumstantial of weather condition alteration, dissimilar researchers have presented this technique to examines the reasons for runoff variations in numerous river basins depend on ancient information.

\section{Acknowledgement}

This research was supported by the Isfahan University of the Technology. We thank our all authors who provided insight and expertise that greatly assisted the research.

\section{Funding Information}

This paper is part of several studies of a group of Researchers, Professors and students of Civil Engineering from Iran. The research group does not receive any funding to support it.

\section{Author's Contributions}

All authors contributed to design the study, write and revise the manuscript.

\section{Ethics}

The present Study and ethical aspect were approved by the Isfahan University of the Technology. The present study was approved by the Isfahan University of Technology.

\section{References}

Abbaspour, K.C., M Vejdani and S. Haghighat, 2007. SWATCUP. Calibration and uncertainty programs for SWAT. Proceedings of the International Congress on Modelling and Simulation, (CMS' 07). Modelling and Simulation Society of Australia and New Zealand, Melbourne, Australia, pp: 1603-1609.

Ahmadi, H., 1999. Applied geomorphology. Tehran University Press.

Bani Asadi, M., 1995. The impact of bam water plumbing plans on the economic situation of residents. J. Watershed Res. Center.

Biroudian, N., 1994. Crisis management. Mashhad University Press.

Castillo, V.M., W.M. Mosch, C. Conesa Garcia, G.G. Barbera and C. Navarro et al., 2007. Effectiveness and geomorphological impacts of check dams for soil erosion control in a semiarid Mediterranean catchment. El Carcavo (Murcia, Spain), Catena, 16: 57-69. DOI: 10.1016/j.catena.2006.11.009
Cheng, J.D., 1989. Stream flow changes after clear cut logging of a pine beetle-Infested watershed in southern British Columbia, Canada. J. Water Resour. Res., 25: 449-456. DOI: $10.1029 /$ WR025i003p00449

Doty, R.D., 1971. Contour trenching effects on stream flow from a Utah watershed. USDA. Forest Service Res. Int.

FAO, 1995. Evaluation and assessment of watershed management project.

Friesecke, F., 2004. Precautionary and sustainable flood protection in Germany-Strategies and instruments of spatial planning. Proceedings of the 3rd FIG Regional Conference, Oct. 3-7, Jakarta, Indonesia, pp: 1-17.

Hyman, E.L., 1985. Monitoring and evaluation of forestry projects for local community development. Agric. Admin., 19: 139-160. DOI: $10.1016 / 0309-586 \times(85) 90033-0$

Karbowski, A., 1993. Optimal flood control in multi reservoir cascade systems with deterministic inflow forecasts. Water Resour. Manage., 3: 207-223. DOI: $10.1007 / \mathrm{BF} 01675304$

IHA, 2001. Iran Hydraulic Association. Hydraul Newsletter.

Khoubfekr, H., 2001. Popular participation, origin of transformation. Sci. J. Agric. Jihad., 254: 107-107.

Kowsar, A., 1993. Technical and economic survey of flood spreading in Fasa aquifer. Res. Instit. Forests Rangelands.

Lammersen, R., H. Engel, W Langemheen and H. Buiteveld, 2002. Impact of river training and retention measures on flood peaks along the Rhine. J. Hydrol., 267: 115-124. DOI: 10.1016/S0022-1694(02)00144-0

Lee, M., G. Park, M. Park, J.Y. Park and J. Lee et al., 2010. Evaluation of non-point source pollution reduction by applying best management practices using a SWAT model and quick bird high resolution satellite imagery. J. Environ. Sci., 22: 826-833. DOI: 10.1016/S1001-0742(09)60184-4

Nash, J.E. and J.V. Sutcliffe, 1970. River flow forecasting through conceptual models. J. Hydrol., 10: 282-290. DOI: 10.1016/0022-1694(70)90255-6

Noble, E.L., 1963. Sediment reduction through watershed rehabilitation. USDA Forest Service, Intermountain Region, Ogden, UT.

Roo, A.D., G. Schmuck, V. Perdigao and J. Thielen, 2003. The influence of historic land use changes and future planned land use scenarios on floods in the der catchment. Phys. Chem. Earth, 28: 1291-1300. DOI: $10.1016 /$ j.pce.2003.09.005

Satterland, J.B., 1962. Soil Conservation ServiceEngineering field manual for conservation practices. 
Shieh, C.L., Y.R. Guh and S.O. Wang, 2007. The application of range of variability approach to the assessment of a check dam on riverine habitat alteration. J. Environ. Geo, 52: 427-435.

DOI: $10.1007 / \mathrm{s} 00254-006-0470-3$

Shokoohi, A.R., 2007. Assessment of urban basin flood control measures using hydrogis tools. J. Applied Sci., 7: 1726-1733.

DOI: $10.3923 /$ jas.2007.1726.1733
Simonovic, P., 2002. Tow non-structural measures for sustainable management of floods. Proceeding of the International Workshop on London, (IWL' 02), Ontario, Canada, pp: 65-81. 